\title{
Emerging Markets and the New Geography of Trade: The Effects of Rising Trade Barriers
}

Reyes-Heroles, Ricardo, Sharon Traiberman, and Eva Van Leemput

Please cite paper as:
Reyes-Heroles, Ricardo, Sharon Trailberman and Eva Van
Leemput (2020). Emerging Markets and the New Geography
of Trade: The Effects of Rising Trade Barriers. International
Finance Discussion Papers 1278.
https://doi.org/10.17016/IFDP.2020.1278

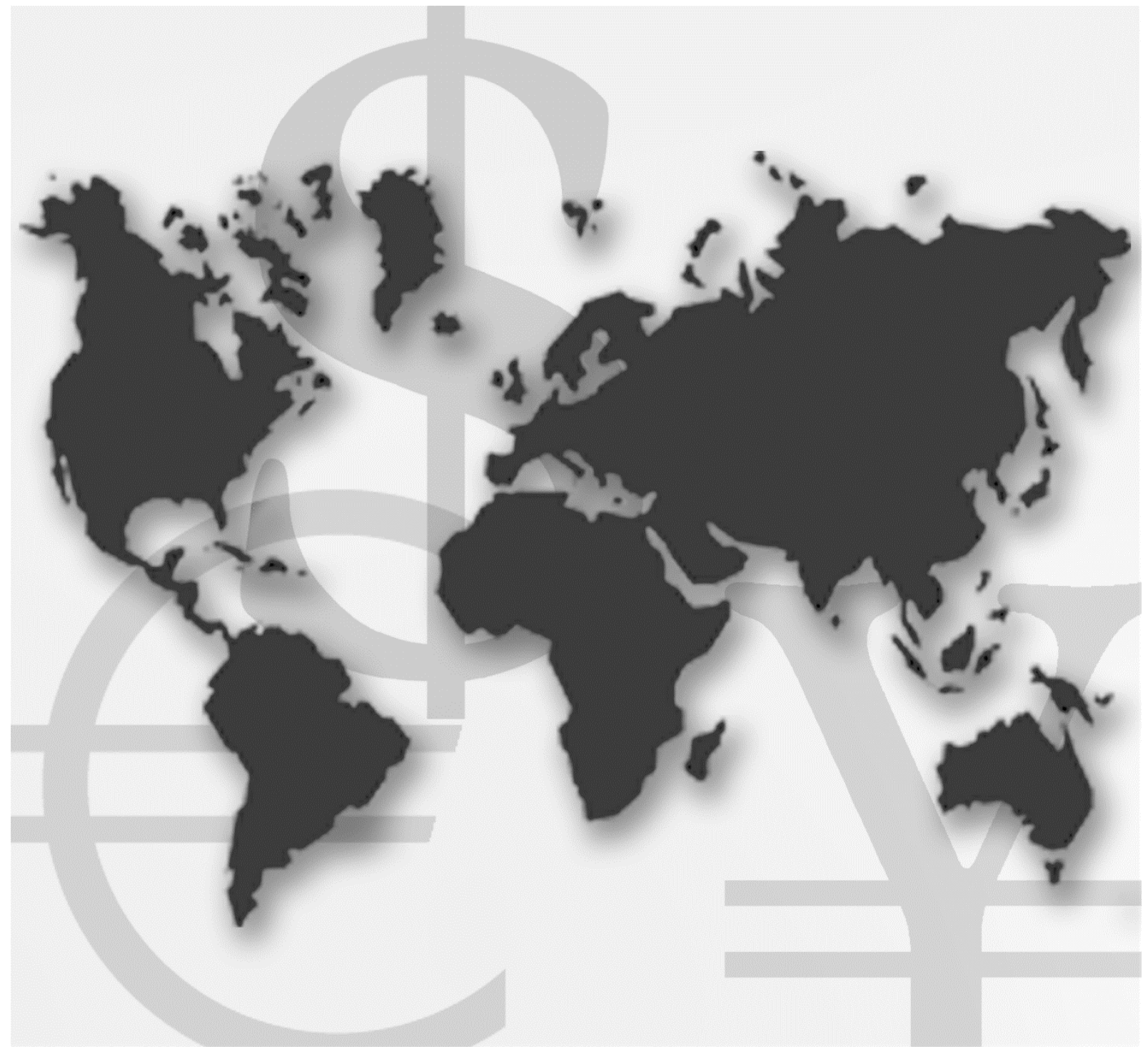

\section{International Finance Discussion Papers}

Board of Governors of the Federal Reserve System

Number 1278

May 2020 


\title{
Board of Governors of the Federal Reserve System \\ International Finance Discussion Papers
}

Number 1278

May 2020

\section{Emerging Markets and the New Geography of Trade: The Effects of Rising Trade Barriers}

\author{
Ricardo Reyes-Heroles, Sharon Traiberman and Eva Van Leemput
}

NOTE: International Finance Discussion Papers (IFDPs) are preliminary materials circulated to stimulate discussion and critical comment. The analysis and conclusions set forth are those of the authors and do not indicate concurrence by other members of the research staff or the Board of Governors. References in publications to the International Finance Discussion Papers Series (other than acknowledgement) should be cleared with the author(s) to protect the tentative character of these papers. Recent IFDPs are available on the Web at www.federalreserve.gov/pubs/ifdp/. This paper can be downloaded without charge from the Social Science Research Network electronic library at www.ssrn.com. 


\title{
Emerging Markets and the New Geography of Trade: The Effects of Rising Trade Barriers*
}

\author{
Ricardo Reyes-Heroles $^{\dagger} \quad$ Sharon Traiberman ${ }^{\ddagger} \quad$ Eva Van Leemput ${ }^{\S}$
}

April 2020

\begin{abstract}
Protectionist sentiments have been rising globally in recent years. The consequences of a surge in protectionist measures present policy challenges for emerging markets (EMs), which have become increasingly exposed to global trade. This paper serves two main purposes. First, we collect several stylized facts that characterize EMs' role in the new geography of trade. We focus on differences between advanced economies (AEs) and EMs in trade linkages, production structures, and factor supplies. Second, we build a dynamic, general equilibrium, quantitative trade model featuring multiple countries, sectors and factors of production. The model is motivated by and geared to jointly match the facts we present. We use the model to estimate the long-run global impacts of rising trade barriers on EMs - both direct impacts and spillovers through third-country effects. Heterogeneity in openness, production structure, trade linkages, and factor supplies leads to large differences between the impacts on AEs versus EMs. We find that variations in both technological comparative advantage and factor supplies play key roles in shaping these differences.
\end{abstract}

JEL classification: E22, F1, F4, F62, O11

Keywords: Emerging market economies, trade barriers, comparative advantage, dynamics

\footnotetext{
*We thank participants at the IMF's 'Current Policy Challenges Facing Emerging Markets' conference, the EIIT conference, and the International Finance workshop (Federal Reserve Board) for valuable comments. We are very grateful to Sebastian Claro for discussing the paper as well as two anonymous referees for constructive comments and suggestions. We also thank Charlotte Singer for excellent research assistance. The views in this paper are solely the responsibility of the authors and should not be interpreted as reflecting the views of the Board of Governors of the Federal Reserve System or of any other person associated with the Federal Reserve System.

${ }^{\dagger}$ Corresponding Author: Federal Reserve Board, Washington, DC 20551. E-mail: ricardo.m.reyes-heroles@frb.gov

${ }^{\ddagger}$ New York University, 19 W. 4th Street, 8th FL, New York, NY 10012. E-mail: sharon.traiberman@nyu.edu

${ }^{\S}$ Federal Reserve Board, Washington, DC 20551. E-mail: eva.vanleemput@frb.gov
} 


\section{Introduction}

Recent years have witnessed a global rise in protectionist sentiment. Moreover, this sentiment has translated into concrete policy as evidenced by Brexit and the tariff increases between China and the United States in 2018 and 2019. Creeping protectionism seems largely to be a backlash to the last two decades of globalization, in which falling barriers and fragmenting supply chains have significantly reconfigured the global economy. The most salient feature of this reconfiguration has been the rise of emerging markets (EMs), such as China and Mexico, both in global production and in global trade flows. Thus, EMs may be particularly vulnerable to both direct trade shocks and the spillovers of indirect trade shocks through supply chain linkages. Studying these linkages quantitatively demands a framework that differs from the standard model used to study EMs. ${ }^{1}$ Such a framework must encompass the new geography of international trade, recognizing EMs as prominent players. Building on several recent advances in the trade literature, we model a global economy featuring EMs and use this model to quantify their role in international trade and the consequences of protectionism for these countries.

Our analysis proceeds in two steps. First, we outline a set of stylized facts characterizing the role of EMs in the new geography of international trade. In particular, we summarize six stylized facts about EMs since the beginning of the century: first, EMs represent a significant share of world trade, especially compared to the past; second, EMs are on average more open than AEs, but there is significant heterogeneity across countries; third, not only have EMs begun to trade more, inter-group trade specifically between EMs and AEs now constitutes half of global trade flows; fourth, intra-group trade between EMs is on the same order of magnitude as trade between AEs; fifth, EMs increasingly trade capital and intermediate goods not just with AEs, but also among each other; and, finally, the factor content of trade differs substantially between EMs and AEs. The first four facts are well known, whereas we believe the last two have received less attention from international economists.

These facts collectively reflect changes in the global order since the end of 1990s, when China joined the WTO (World Trade Organization), the EU expanded to include Eastern European partners, and the BRICS countries rose in prominence. To motivate our exercise of building a model that speaks to these facts, it helps to contrast our focus with that of the trade literature up until the recent rise of China, which led to a shift in focus. For most of the 20th century, the

\footnotetext{
${ }^{1}$ Végh (2013) presents and discusses the typical macroeconomic approach to studying EMs.
} 
trade literature had documented substantial trade between countries similar in endowments and technology levels - so-called "North-North" trade - and little trade with developing countries - socalled "North-South" trade. The seeming failure of classical theories, such as Heckscher-Ohlin (HO), to explain trade patterns led to the development of new theories that could explain trade between similar countries. Hence, when EMs were studied, they were often treated as small open economies (SOEs). Interestingly, the new geography of trade suggests that this latter assumption is outmoded, and some of the classical theories may play a role yet again. In particular, not only are trade costs, Ricardian comparative advantage, and input-output linkages important, but so are multiple factors of production.

With these facts in hand, we build a quantitative model to match them, demonstrate which model ingredients are key to understanding EMs, and, finally, determine how these ingredients shape our understanding of the impacts of rising trade barriers on EMs. Specifically, we build a dynamic, multi-country, multi-sector, multi-factor general equilibrium quantitative model of international trade. Despite the growth of powerful quantitative models in the trade literature, there has been little analysis of the global impacts of recent changes in trade barriers, especially for EMs. ${ }^{2}$ Our model uses several new tools from this literature to capture the forces that underlie and explain our facts. Our model departs from the standard literature in two key respects. ${ }^{3}$ First, we add Heckscher-Ohlin forces by allowing factor supplies to differ across countries and factor intensities to differ across sectors. We also add endogenous investment and capital accumulation. Once we have a model that can speak to the rise of EMs and how they differ from AEs, we can turn to counterfactual predictions of how trade barriers will impact EMs in both the short and long run.

Our calibrated model serves as a laboratory to perform three quantitative exercises. In our first exercise, we simulate a uniform 5 percentage point increase in trade costs everywhere. Increasing trade barriers has a sizable negative impact on global output and welfare. However, while the average effect across AEs and EMs is broadly similar, there are large within-group differences. The variance in outcomes is much larger across EMs. This result is not mechanical in any sense, as there are no modeling assumptions that differ by country. Instead, it is because EMs are particularly heterogeneous in their exposure to trade shocks through differences in their production structure and factor supplies. As imports tend to be capital-intensive, initial cross-country differences in trade exposure are amplified through endogenous investment. Interestingly, we find that higher worldwide

\footnotetext{
${ }^{2}$ One exception without a focus on EMs is Charbonneau and Landry (2018).

${ }^{3}$ See, for example, Caliendo and Parro (2015).
} 
tariffs redistribute world export activity toward EMs, which ameliorates much of the direct welfare loss to consumers and producers facing higher prices.

Our second and third experiment model two recent - and dramatic - escalations of protectionism: Brexit and the 2018-2019 US-China trade war. In the event of a 'no trade deal' Brexit, we find meaningful negative effects for most AEs, especially for Britain, Ireland and countries in the EU. Even though AEs switch expenditure toward goods produced in EMs, this shift is minuscule, implying that the spillover effects are not considerable. Within the set of EMs, most output growth occurs in China. Regarding the US-China trade war, the tariffs have particularly driven up the price of investment goods, which depresses investment and GDP. While both China and the US suffer, spillover effects are broadly positive for other countries, with other EMs especially benefiting.

We close the paper by discussing why the Heckscher-Ohlin forces and investment channel is important for understanding the effects of trade barriers on EMs. In particular, these two forces interact to determine how capital stocks change in equilibrium. We also calibrate a simplified version of the model in order to model transition dynamics and the endogenous response of trade balances to shocks. We discuss the difficulties in calculating transition dynamics in the full model, but see this issue as the key avenue for future work.

This paper contributes to both the international trade and international macro literature. First, our empirical analysis complements the heretofore scarce work on EMs and their role in shaping world trade flows. Hanson (2012) is one of the few papers that has focused specifically on the recent role of EMs in global trade. He studies the increase in trade among EMs and between EMs and AEs from the late 1990s until the Great Recession. ${ }^{4}$ We update, expand, and extend this collection of facts, characterizing the idea of a "new geography of international relations" put forward by UNCTAD (2004). Our finding of an increased role of EMs in trade in capital goods is particularly relevant and contrasts with what Eaton and Kortum (2001) have documented in the past. While the international macroeconomics literature has made significant progress on characterizing several features of EMs, such as business cycles ${ }^{5}$, our facts on capital and investment goods explicitly link trade to economic fluctuations and growth.

The model we develop contributes to the growing literature that uses large general equilibrium models to understand the importance of new features of the global economy and to simulate the

\footnotetext{
${ }^{4}$ Timmer et al. (2014) also point out some recent features of trade in value added for EMs. However, their focus is not on this set of countries in particular.

${ }^{5}$ For example, see Neumeyer and Perri (2005), Uribe and Yue (2006), Aguiar and Gopinath (2007), Mendoza (2010), and García-Cicco et al. (2010). See Montiel (2011) and Végh (2013) for overviews of macroeconomics in EMs.
} 
impact of future changes to the trade environment - whether they be technological or political. Our model is most closely related to Parro (2013), who incorporates multiple factors of production and capital-skill complementarity into a multi-sector extension of Eaton and Kortum (2002) with input-output linkages (Caliendo and Parro, 2015; Levchenko and Zhang, 2016). We add endogenous investment, building on Alvarez (2017) and Ravikumar et al. (2019). The multi-factor and investment channels play a key role in shaping the response of different EMs to trade shocks but have been absent from quantitative analyses of recent tariff hikes (e.g., Charbonneau and Landry (2018); IMF $(2019))$.

The rest of the paper is organized as follows. In Section 2 we carry out our empirical analysis and document six facts on trade in EMs. In Section 3 we present the model and define a steady-state equilibrium. Section 4 introduces the data and how we map the model to these data. Section 5 presents the quantitative results of our policy experiments and counterfactuals. Section 6 explores the implications of HO-type forces and discusses transitional dynamics. Section 7 concludes.

\section{Emerging Markets and the New Geography of Trade: Stylized Facts}

In this section, we document six stylized facts about EMs' trade patterns. While our focus is on trade patterns today, we present data from the 1990s to put the rapid rise of EMs in perspective. We update and complement well-documented facts (see, e.g., Chapter 1 of Feenstra and Taylor (2017), Hanson (2012), or Timmer et al. (2014)). However, we also bring in new facts on the composition of goods traded and factors used across countries. In doing so, we try to unpack the forces driving intra-group trade and distinguish from forces driving inter-group trade. Our main sources of data are the UN Comtrade Database, the IMF World Economic Outlook (WEO), and the World Input Output Database (WIOD). When possible, ${ }^{6}$ we include 56 countries in our sample — 35 AEs, 21 EMs-and a rest of world aggregate. Appendix A provides additional details on data sources and availability.

\section{Fact 1: Trade by EMs represents a significant share of world trade.}

Figure 1 shows total EMs exports as a fraction of total world exports. Since 2010, EMs have been a globally important source of export activity, accounting for nearly 45 percent of global

\footnotetext{
${ }^{6}$ Only 20 AEs and 13 EMs are available for the factor analysis.
} 
exports compared with only 25 percent in 1996. Importantly, this growth is broad based and not driven solely by China. ${ }^{7}$ Indeed, the share of exports accounted for by EMs besides China has grown from $20 \%$ to nearly $30 \%$. This rapid ascent has been documented before, and our focus will be in understanding the technology and trade costs that shape the seeming steady state since 2010 .

Figure 1: EM Export Share (share of world exports)

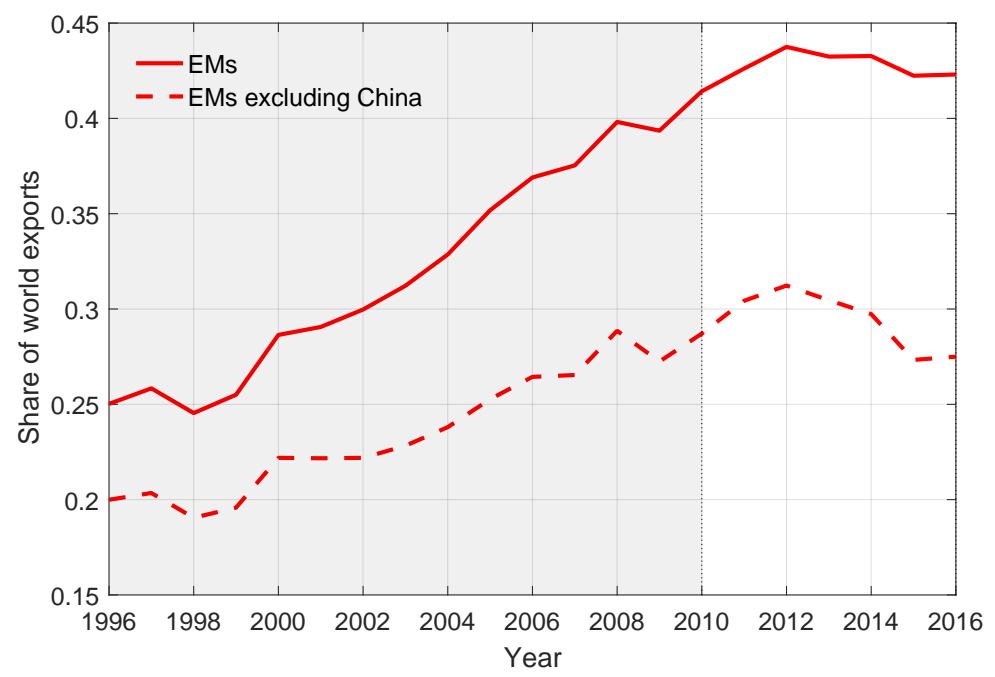

As our ultimate goal is for these facts to guide our quantitative model, we see the rise of EMs in global trade as evidence of the need to incorporate general equilibrium forces into any quantification of the effects of rising trade barriers. EMs are no longer SOEs, but countries whose actions and economic fortunes spill over to other EMs and AEs.

\section{Fact 2: Emerging markets are, on average, more open than advanced economies, but there is great heterogeneity across countries.}

Figure 2 plots the evolution of our preferred measure of trade openness for both EMs and AEs. We define trade openness as the ratio of exports to GDP. For each group, we plot the GDP-weighted average of this measure as well as the value at the 75 th and 25th percentile across countries. EMs are actually more open than AEs, and this fact has been true for the entire sample period. Right before the Great Financial Crisis (GFC), the openness of EMs (30 percent) was nearly double that of AEs (17 percent). Since the end of the GFC, the openness measures have moved closer together.

\footnotetext{
${ }^{7}$ Feenstra and Taylor (2017) contains many more deatails on the growth of China in particular.
} 
Figure 2: EM and AE Trade Openness (exports as a share of GDP)

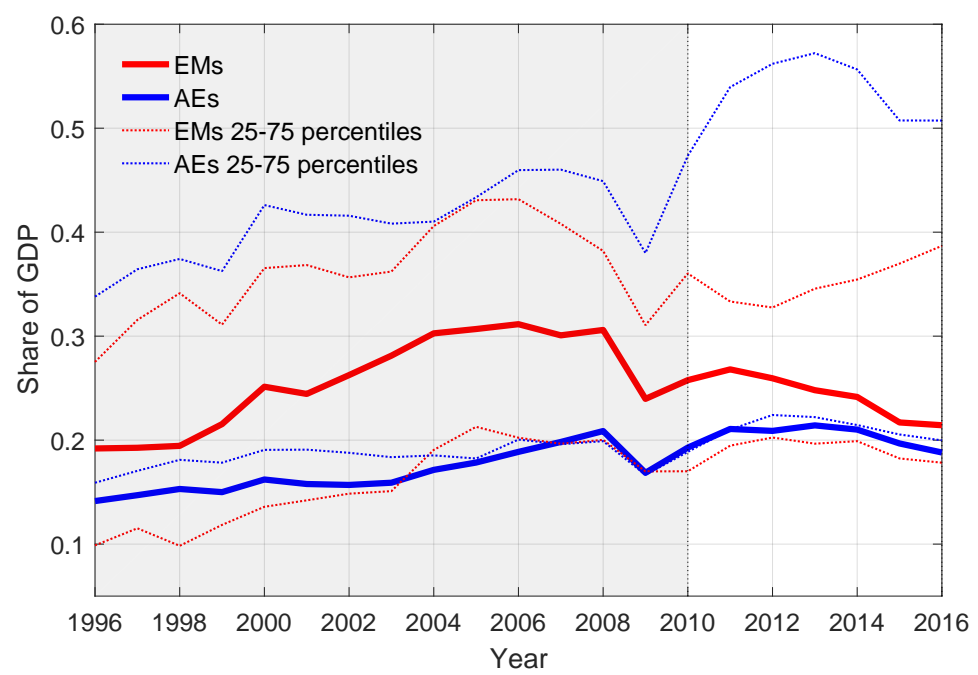

The average obscures the substantial heterogeneity across countries. The 25 th and 75 th percentile bands show that there is huge overlap in the openness measure for most AEs and EMs. Hence, some EMs are very similar to AEs in trade openness. Moreover, the most open AEs actually appear to be more open than their EM counterparts. We take this fact as evidence for the need to include heterogeneity in trade openness between EMs and AEs as well as within each group. In appendix $\mathrm{D}$ we show that the preceding discussion is robust to different measures of openness and to the exclusion of China.

\section{Fact 3: Trade between EMs and AEs represents a significant share of global trade.}

Now we characterize trade between EMs and AEs versus trade within these respective groups. The rise of EMs is consistent with a world of multiple trading blocks, with EMs largely buying and selling to particular AEs, or with a globally dense set of interconnections. We show that this latter arrangement describes modern EMs. To do so, we compute two measures of trade: (1) trade linkages among AEs and among EMs, which we define as intra-group trade, and (2) trade linkages between AEs and EMs, which we define as inter-group trade. ${ }^{8}$ Figure 3 shows that exports across groups, rather than within, currently account for nearly half of world exports. Even if one ignores

\footnotetext{
${ }^{8}$ Specifically, letting $i, h$ index countries, denoting EMs by $\mathcal{E}$ and AEs by $\mathcal{A}$, our measures of intra- and inter-group trade are computed as follows.

1. Intra-group trade:

$$
\frac{\sum_{h \in \mathcal{A}} \sum_{i \in \mathcal{A}} X_{i h, t}+\sum_{h \in \mathcal{E}} \sum_{i \in \mathcal{E}} X_{i h, t}}{\sum_{h \in \mathcal{I}} \sum_{i \in \mathcal{I}} X_{i h, t}} .
$$
}


Figure 3: Intra- and Inter-group Trade Linkages (share of world exports)

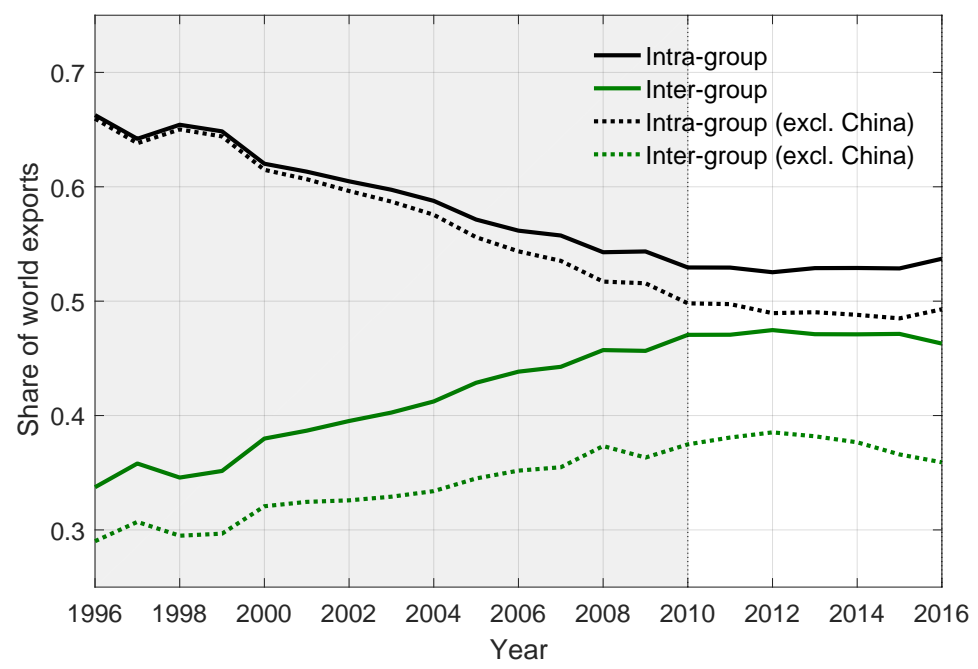

the meteoric rise of China, inter-group trade now accounts for nearly 40 percent of world exports. This pattern is in sharp contrast to trade before the 2000s, which was dominated by AEs and spurred the huge literature on North-North trade. However, as the role of EMs in global trade has grown in importance, the predominance of North-North trade needs to be revisited. Today, both inter- and intra-group trade are equally important features of the global economy. Moreover, the fact that there is as much trade across groups as within groups suggests that our model must allow for comparative advantage differences across EMs and AEs that are on the same order of magnitude as between EMs and AEs.

\section{Fact 4: As a share of global trade, intra-group trade for EMs represents a significant share of total intra-group trade.}

Next, we break down trade patterns among EMs and AEs. We disentangle the previous measure of intra-group trade into (1) trade among AEs and (2) trade among EMs as a share of world trade. Figure 4 plots these two measures together with the same intra-group measure as in Figure 3. Interestingly, there has been a decline in trade-group trade, but this trend is entirely driven by the decline in importance of trade among AEs, which has fallen from 60 percent of global exports

2. Inter-group trade:

$$
\frac{\sum_{h \in \mathcal{A}} \sum_{i \in \mathcal{E}} X_{i h, t}+\sum_{h \in \mathcal{A}} \sum_{i \in \mathcal{E}} X_{i h, t}}{\sum_{h \in \mathcal{I}} \sum_{i \in \mathcal{I}} X_{i h, t}} .
$$


Figure 4: Intra-group Trade (share of world exports)

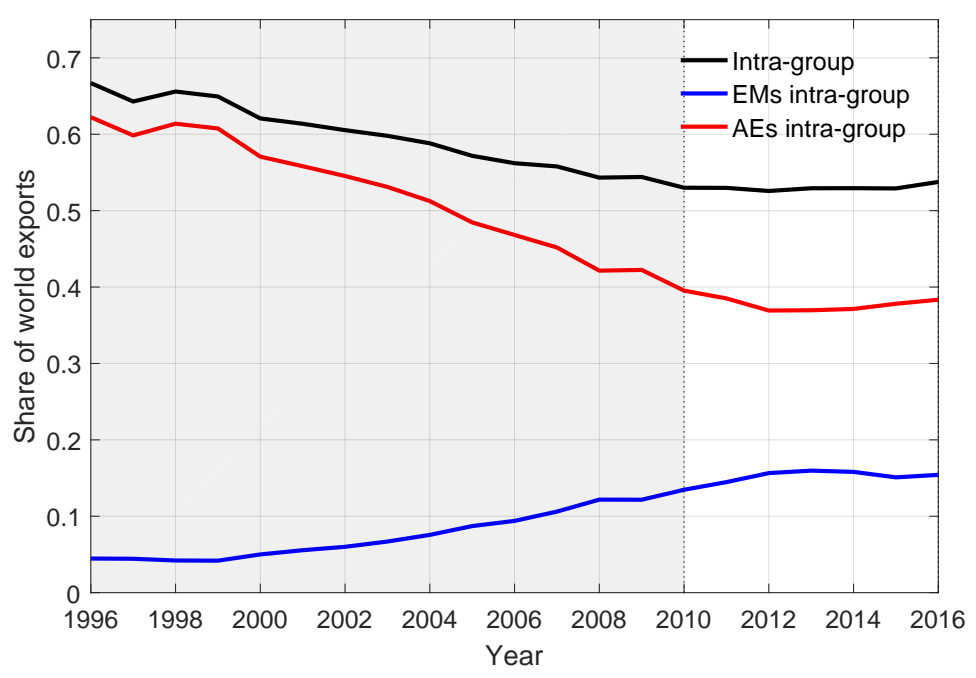

to 40 percent. In contrast, trade among EMs has more than tripled, from 4 to 15 percent of global exports. ${ }^{9}$ The resulting lesson for our model echoes that of the previous fact: within-group heterogeneity is important for understanding EMs in the modern economy.

\section{Fact 5: EMs produce and consume both intermediate and capital goods, but het- erogeneously.}

By now it should be clear that EMs are substantial players in the global economy - the era of trade dominated by similar countries has given way to a more integrated world. However, does that circumstance imply that models developed to explain this former era are ill equipped to understand trade today? In this fact we show that EMs produce and import different goods than AEs, which militates against theories based on variety trade among similar countries. However, we also show that trade in intermediates has grown - highlighting the role of input-output linkages and global value chains. We also document an important fact that pushes us toward a dynamic model of trade: a substantial chunk of EM trade (both with AEs and among each other) is in capital and investment goods.

First, we document the place of EMs in the rise of global value chains (GVCs). GVCs refer to the fragmentation of the stages of production for a single good across space. Their growth, and the consequent rise in intermediate goods trade has been discussed by Johnson (2014). To analyze

\footnotetext{
${ }^{9}$ Excluding China has little impact: the intra-EM share grows from 4 to 9 percent.
} 
intermediates trade done by EMs, we first disaggregate total trade among and between AEs and EMs into two types of traded goods following the Broad Economic Categories (BEC) classification: (1) trade in intermediate goods and (2) trade in capital goods. ${ }^{10}$

Figure 5: Importance of EMs in Intermediate and Capital Goods Trade

(a) Intermediate Goods (share of intermediate exports)

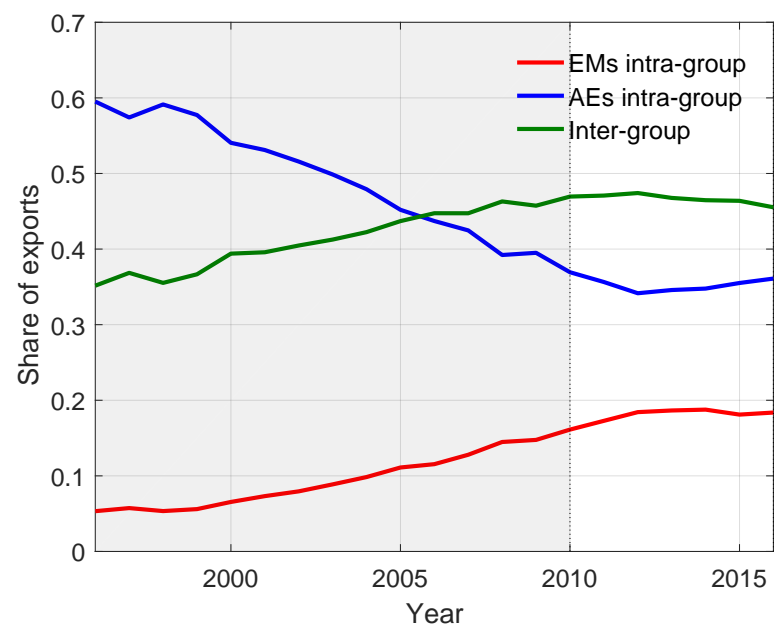

(b) Capital Goods (share of capital exports)

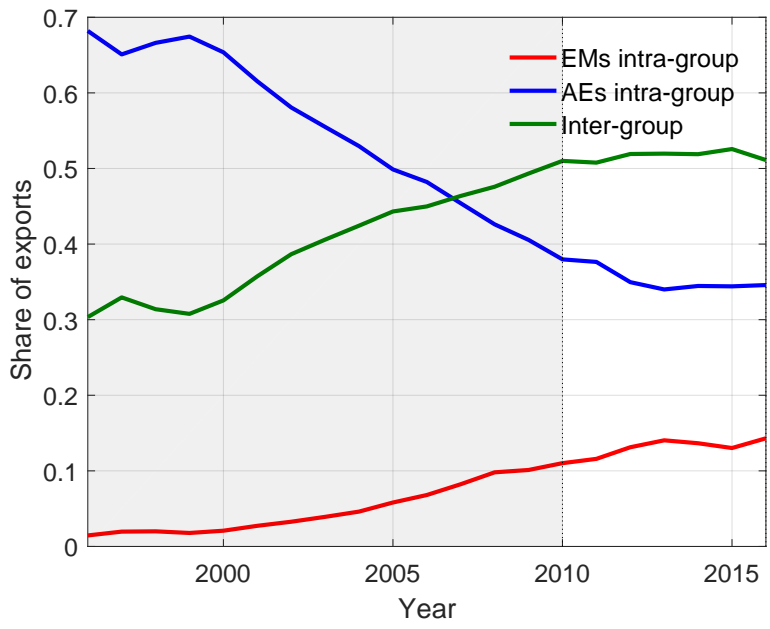

The left panel in Figure 5 shows the breakdown of the same three trade patterns as in Figure 4 for intermediate goods trade as a share of total intermediate goods trade. It highlights that the share of trade among AEs has also declined for intermediate goods. In contrast, the share of intermediate goods trade among EMs has increased significantly, as have trade flows between the groups. This latter fact points to a standard view of GVCs, where EMs might perform some tasks before shipping an intermediate to AEs for finishing. But, as we have stressed above, this uncomplicated view cannot explain the within-EM trade. This fact is explained by heterogeneity in comparative advantage across EMs, where they specialize in different pieces of the value chain that may nevertheless be of similar value or complexity.

Regarding to capital goods trade, the right panel in Figure 5 shows the same breakdown for all three trade patterns pairs. The same patterns emerge for capital goods trade as they did for intermediate goods trade: capital goods trade between AEs as a share of global capital goods trade has declined dramatically, while for EMs it has soared. For example, capital goods trade among EMs was almost non-existent in 1996 but has risen to about 15 percent of global capital goods

\footnotetext{
${ }^{10}$ See Appendix B for the breakdown of each category. Among these two categories, intermediate goods trade accounts for more than half - 56 percent in 2016 - of total goods trade whereas capital goods account for 17 percent. The BEC classification also includes consumption goods trade as a separate category. The patterns are similar to those documented for intermediate and capital goods.
} 
trade. In an influential paper, Eaton and Kortum (2001) show that in the 1990s almost all world exports of capital goods were from only a few AEs. Figure 5 clearly shows that this common view of trade in capital goods is outdated, and as far as we are aware this is a new finding. The growth in importance of EMs in capital goods trade points to a connection between trade and investment in these economies and motivates our inclusion of investment decisions in the subsequent structural model.

Figure 6: Trade among EMs (share of category's exports)

(a) Intermediate Goods

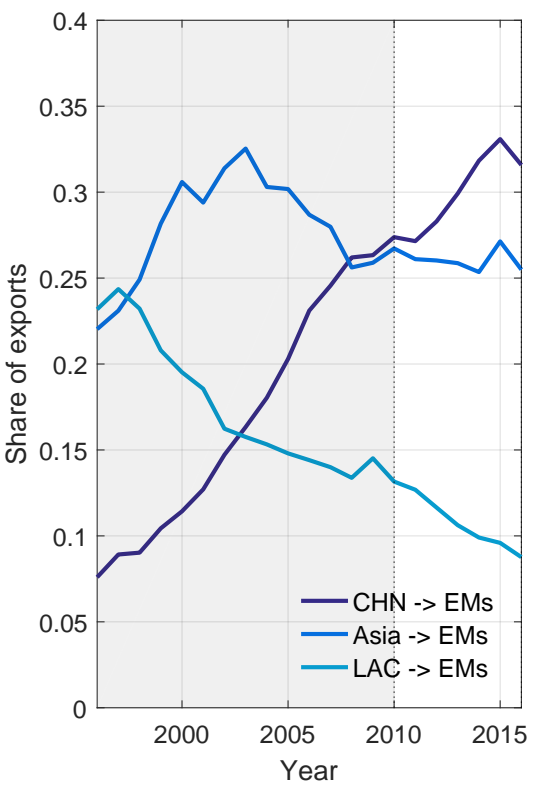

(b) Non-oil Commodities

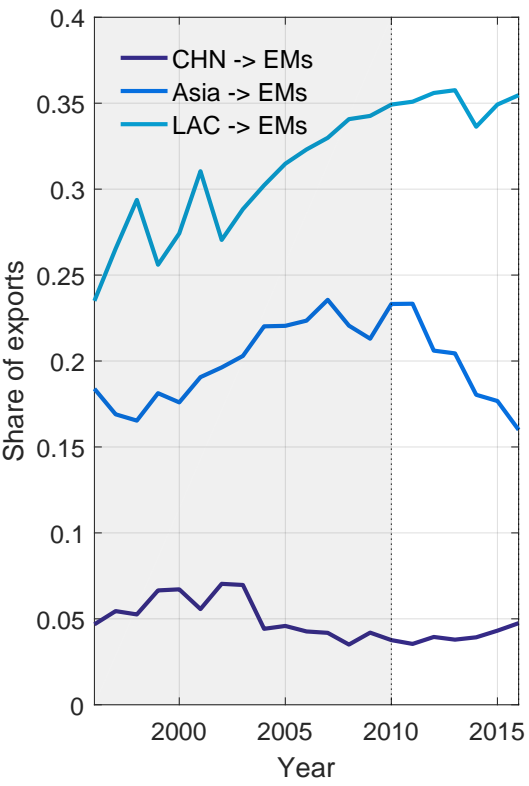

(c) Capital Goods

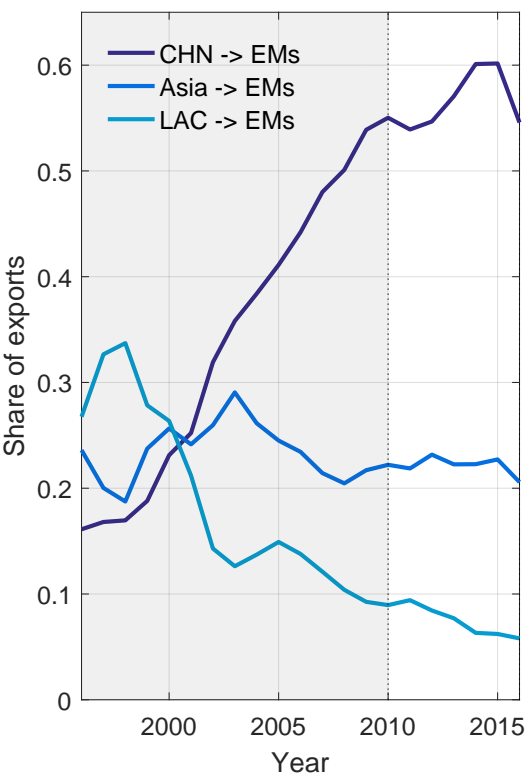

Given the increasing role of trade among EMs in global trade, we study regional patterns of trade. We are particularly interested in whether the growth in intermediates simply reflects a commodities boom in a few EMs. This possibility turns out not to be the case, albeit both commodities and other intermediates matter. To illustrate this, we decompose within-EM trade into three main categories: (1) intermediate goods, (2) commodities, and (3) capital goods. ${ }^{11}$ Figure 6 plots the share of regional trade with other EMs as a share of total EM trade in each good category. For instance, the solid black line in the left panel shows China's intermediate goods trade with other EMs as a share of total intermediate goods trade among EMs.

The left panel in Figure 6 highlights that trade in intermediate goods is dominated by China and the Asian EMs. Latin American countries represent a small share of intermediate trade. In contrast,

\footnotetext{
${ }^{11}$ See Appendix B for the breakdown of each category.
} 
Latin American countries account for the largest share of non-oil commodities trade to other EMs, as shown in the middle panel. Finally, the right panel shows trade in capital goods. Interestingly, China's share of capital goods exports to other EMs has soared over the past two decades from just under 20 percent in 1996 to 60 percent in 2016. These patterns of trade suggest that EMs differ among themselves in terms of comparative advantage, especially between commodity exporters and exporters of manufactures. Not only do these patterns document how EMs have integrated themselves into global value chains, but they suggest that the implications of trade shocks may be very different across EMs, at least in comparing Latin America and Asia.

All told, the patterns we highlight here point toward the need for a model that allows for production heterogeneity and investment for EMs. Before showing how we can integrate these forces into a quantitative model, we turn to our final fact: the stark differences in factor supplies across EMs and AEs.

\section{Fact 6: Factor endowments are key to understanding AE-EM trade.}

It is well known that countries differ dramatically in factor supplies - specifically, skilled versus unskilled labor - but it is less clear how much this fact matters in explaining trade patterns. A large literature in the 1990s documented the failure of factor-based models of trade and the simultaneously low level of trade between countries at different stages of development. ${ }^{12}$ To explore how important differences in factor supplies are in explaining trade between AEs and EMs today, we compute the skill content of net trade for each of the countries in our sample and demonstrate that these contents are systematically different across AEs and EMs. ${ }^{13}$ The factor content of trade is an intuitive construct: it uses an economy's production structure to map trade in output into the implied trade in inputs (factors). We follow the method of Trefler and Zhu (2010), which allows one to construct the factor content of trade in a world of input-output links. We compute the skilled labor content of trade, $F H$, and unskilled labor content of trade, $F L$, and define the skill bias of net trade as FH - FL. Figure 7a displays our skill bias measure across all countries, averaged over time.

The figure's results fit intuitions: AEs tend to export high-skilled labor (or import low-skilled labor), and the opposite is true for EMs. Moreover, the differences in these numbers are large. For example, the US, Japan, and Germany export altogether nearly as much high-skilled labor as China

\footnotetext{
${ }^{12}$ Classic works here include Davis and Weinstein (2001) and Trefler (1995), while examples of more recent work can be found in Trefler and Zhu (2010) and Morrow and Trefler (2017).

${ }^{13}$ We use data from the WIOD 2012 release, as the more recent release does not report data for different skills.
} 
Figure 7: Skill Bias of Net Trade $(F H-F L)$ Across Countries and Over Time

(a) Skill Bias of Net Trade (average 1995-2009)

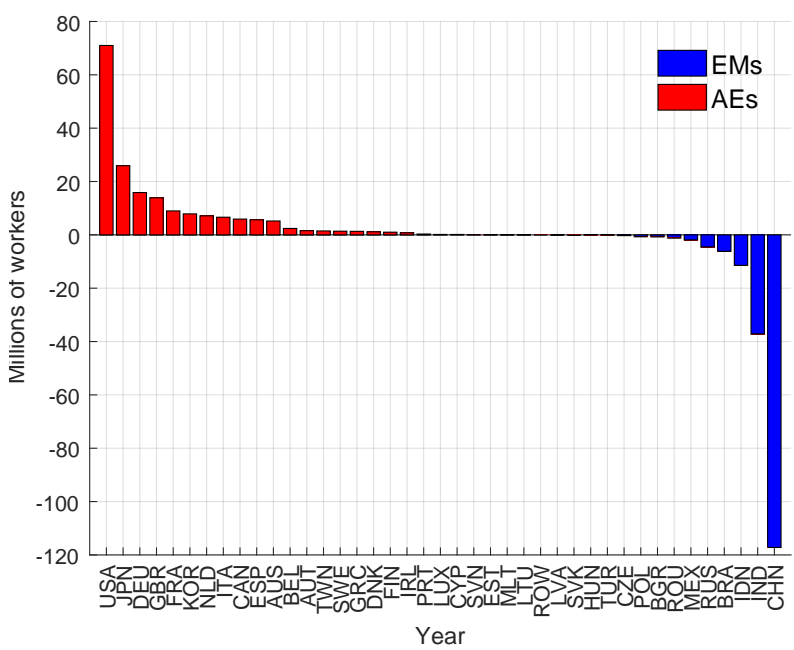

(b) Skill Bias of Net Trade (country-group total)

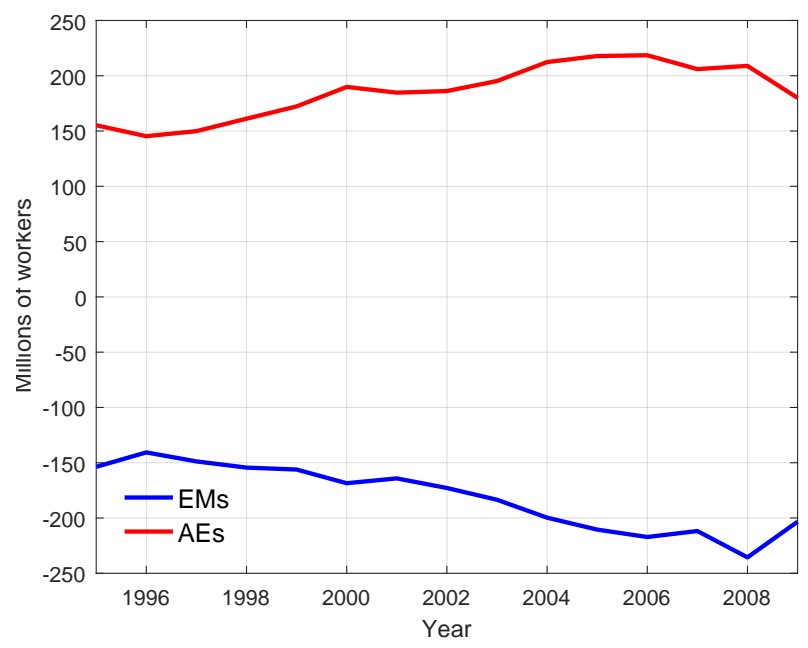

exports low-skilled labor. Indeed, the five largest net exporters of high-skilled labor are all AEs, while the top five exporters of low-skilled labor are all EMs.

The time series evidence reinforces, and actually amplifies, the cross-sectional evidence. Figure $7 \mathrm{~b}$ plots the average skill bias of factor content for each group of countries. From the figure one can see that not only is the difference large, but it is growing over time. Hence, despite a general increase in skilled labor across the world, AEs seem to be disproportionately increasingly specialized in high-skilled intensive goods. Facts 5 and 6 call for a reevaluation of the role of HO forces - emphasizing multiple factors and sectors - in shaping trade across countries.

\section{The Model}

In this section, we develop a quantitative model of international trade that incorporates the facts documented in Section 2. We consider a dynamic model with multiple factors of production and use this model to explore the macroeconomic effects of changes in trade barriers on EMs as well as on the world economy overall. We first describe endowments, technologies and households' preferences, and then we turn to the characterization of optimal decisions by firms and households as well as market clearing conditions. 


\subsection{Endowments, Technologies and Households}

We consider an infinite-horizon world economy. Time is discrete and indexed by $t=0,1, \ldots$ The world consists of $I$ countries indexed by $i$. Each country is populated by a representative household endowed with $S_{i, t}$ units of skilled labor and $U_{i, t}$ units of unskilled labor in every period $t$ and $K_{i, 0}$ units of homogeneous physical capital in period $t=0$. Neither labor nor capital is tradable.

The economy of each country consists of $J$ sectors indexed by $j$. Sectoral goods are non-tradable across countries. They are produced by aggregating a continuum of tradable sector-specific varieties. Non-tradable sectoral goods can be used for consumption, investment or as intermediate inputs in the production of sector-specific varieties.

\subsubsection{Technologies: Non-tradable Sectoral Goods}

Final output in each sector $j$ is given by a constant elasticity of substitution (CES) aggregator of a continuum of tradable goods, indexed by $\omega^{j} \in[0,1]$, with elasticity of substitution $\eta>0$. Denoting by $Q_{i, t}^{j}$ sector $j$ 's final output in country $i$ at time $t$, we have that

$$
Q_{i, t}^{j}=\left(\int_{0}^{1} d_{i, t}^{j}\left(\omega^{j}\right)^{\frac{\eta-1}{\eta}} d \omega^{j}\right)^{\frac{\eta}{\eta-1}}
$$

where $d_{i, t}^{j}\left(\omega^{j}\right)$ denotes the use in production of intermediate good $\omega^{j}$.

The demand for each intermediate good is derived from the cost minimization problem of a price-taking representative firm. Moreover, because good $\omega^{j}$ is tradable across countries, the firms producing $Q_{i, t}^{j}$ search across all countries for the lowest-cost supplier of this good.

The final output in each sector $j$ is non-tradable and can be used either for final consumption, for investment or as an intermediate input into the production of the tradable goods. We will denote by $P_{i, t}^{j}$ the price of sectoral good $j$ in country $i$ at time $t$. Let us now focus on the technologies available to produce the tradable goods indexed by $\omega^{j}$.

\subsubsection{Technologies: Tradable Goods}

Consider a particular good $\omega^{j} \in[0,1]$ and let $q_{i, t}^{j}\left(\omega^{j}\right)$ denote the production of this good in country $i$ at time $t$. We consider a technology to produce each good $\omega^{j}$ that is flexible enough to accommodate different elasticities of substitution across factors of production. 
Each good $\omega^{j}$ is produced according to

$$
q_{i, t}^{j}\left(\omega^{j}\right)=x_{i, t}^{j}\left(\omega^{j}\right)\left[V_{i, t}^{j}\left(\omega^{j}\right)\right]^{\nu_{i}^{j}}\left[M_{i, t}^{j}\left(\omega^{j}\right)\right]^{1-\nu_{i}^{j}}
$$

where $V_{i, t}^{j}\left(\omega^{j}\right)$ is the amount of value added in production of good $\omega^{j}$ and $M_{i, t}^{j}\left(\omega^{j}\right)$ denotes the amount of intermediates used in production. Value added is in turn given by

$$
V_{i, t}^{j}\left(\omega^{j}\right)=\left[\left(\gamma_{i}^{j}\right)^{\frac{1}{\sigma}} u_{i, t}\left(\omega^{j}\right)^{\frac{\sigma-1}{\sigma}}+\left(1-\gamma_{i}^{j}\right)^{\frac{1}{\sigma}} Z_{i, t}\left(\omega^{j}\right)^{\frac{\sigma-1}{\sigma}}\right]^{\frac{\sigma}{\sigma-1}}
$$

where $Z_{i, t}$ denotes the composite factor of production that aggregates physical capital and skilled labor and is given by

$$
Z_{i, t}^{j}\left(\omega^{j}\right)=\left[\left(\varphi_{i}^{j}\right)^{\frac{1}{\rho}} k_{i, t}\left(\omega^{j}\right)^{\frac{\rho-1}{\rho}}+\left(1-\varphi_{i}^{j}\right)^{\frac{1}{\rho}} s_{i, t}\left(\omega^{j}\right)^{\frac{\rho-1}{\rho}}\right]^{\frac{\rho}{\rho-1}}
$$

We assume that the use of intermediates in production is given by a Cobb-Douglas aggregate of non-tradable sectoral goods:

$$
M_{i, t}^{j}\left(\omega^{j}\right)=\prod_{m=1}^{J} D_{i, t}^{j, m}\left(\omega^{j}\right)^{\alpha_{i}^{j, m}}
$$

where $\sum_{m=1}^{J} \alpha_{i}^{j, m}=1$ for all $j=1, \ldots, J$ and $\alpha_{i}^{j, m} \in(0,1)$ for all $j, m=1, \ldots, J$. Here, $D_{i, t}^{j, m}\left(\omega^{j}\right)$ denotes the intermediate demand by producers of good $\omega^{j}$ for sectoral good $m$. The efficiency in the production of good $\omega^{j}$ is given by $x_{i, t}^{j}\left(\omega^{j}\right)$. Note that the country- and sector-specific parameter $\nu_{i}^{j} \in(0,1)$ determines the share of value added in gross production, while $\alpha_{i}^{j, m}$ for all $j, m=1, \ldots, J$ determine the input-output structure in each country.

Following Eaton and Kortum (2002), we assume the efficiency in the production of good $\omega^{j}$, $x_{i, t}^{j}\left(\omega^{j}\right)$, is given by the realization of a random variable, $x_{i, t}^{j} \in(0, \infty)$, that is distributed, conditional on information in period $t$, according to a Fréchet distribution with shape parameter $\theta^{j}$ and location parameter $T_{i, t}^{j}$,

$$
F_{i, t}^{j}(x \mid t)=\operatorname{Pr}\left[x_{i, t}^{j} \leq x\right]=e^{-T_{i, t}^{j} x^{-\theta^{j}}}
$$

We assume that the random variables $x_{i, t}^{j}$ are independently distributed across sectors and countries. In that case, the level of $T_{i, t}^{j}$ represents a measure of absolute advantage in the production of sector $j$ goods, while a lower $\theta^{j}$ implies more dispersion across the realizations of the random variable and a higher scope for gains from comparative advantage differences through specialization. 
We refer to $T_{i, t}^{j}$ as the sectoral productivity of country $i$ in sector $j$ at time $t$, as they summarize the level of the distribution from which producers draw their efficiencies. Because productivity can change over time, exogenous permanent changes in these parameters can lead the world economy to transition from one steady state to a new one.

\subsubsection{Households}

The dynamic dimension of the model results from the household's saving and investment decisions. We assume that investment is only possible in physical capital and that evolution of relative skills in each country is exogenously given. ${ }^{14}$ We consider the benchmark case in which financial markets are frictionless, which implies that the return on international assets - denominated in a single currency - is the same for all countries.

The problem of the representative household in country $i$ is choosing sectoral levels of consumption and investment as well as aggregate investment and savings to maximize lifetime utility. Thus, the household in country $i$ must choose, for every $t=0,1, \ldots$, consumption and investment levels in each sector as well as next period's aggregate capital stock and bond holdings, $\left\{\left\{C_{i, t}^{j}\right\}_{j \in \mathcal{J}},\left\{X_{i, t}^{j}\right\}_{j \in \mathcal{J}},, K_{i, t+1}, B_{i, t+1}\right\}_{t=0}^{\infty}$, in order to maximize lifetime utility $\sum_{t=0}^{\infty} \beta^{t} \ln \left(C_{i, t}\right)$. $C_{i, t}$ is aggregate consumption, which is a function of sectoral consumption levels, to be defined next. Bond holdings at the end of period $t, B_{i, t+1}$, are subject to portfolio adjustment costs. In particular, the cost of holding $B_{i, t+1}$ bonds is given by $\frac{\psi}{2}\left(B_{i, t+1}-\bar{B}_{i}\right)^{2}$, where $\bar{B}_{i}$ is exogenous. ${ }^{15}$ The choices by the representative household are subject to the budget constraint,

$$
\sum_{j=1}^{J} P_{i, t}^{j}\left(C_{i, t}^{j}+X_{i, t}^{j}\right)+B_{i, t+1}+\frac{\psi}{2}\left(B_{i, t+1}-\bar{B}_{i}\right)^{2}=w_{i, t}^{U} U_{i, t}+w_{i, t}^{S} S_{i, t}+r_{i, t} K_{i, t}+R_{t} B_{i, t}+\mathcal{T}_{i, t}
$$

as well as to the law of motion for capital,

$$
K_{i, t+1}=X_{i, t}+(1-\delta) K_{i, t}
$$

in every period $t=0,1, \ldots$, where $\mathcal{T}_{i, t}$ are tariff revenues that are rebated to households in a lump

\footnotetext{
${ }^{14}$ Our model does not consider the possibility of endogneous changes in relative skills through investment in human capital after a shock to trade barriers. We consider this as a relevant channel of adjustment in the very long run, but do not incorporate it to keep our model tractable.

${ }^{15}$ We model these costs following Neumeyer and Perri (2005). We choose this route to introduce trade imbalances in steady state because it introduces stationarity into the model. This feature simplifies the computation of counterfactual equilibria in steady state considerably, as we further discuss in section 6. See Reyes-Heroles (2017) for a similar, but non-stationary model.
} 
sum fashion. ${ }^{16}$ Aggregate consumption and investment in the representative household's problem, $C_{i, t}$ and $X_{i, t}$, are given by Cobb-Douglas aggregates of sectoral consumption and investment levels, respectively:

$$
C_{i, t}=\prod_{j=1}^{J}\left(C_{i, t}^{j}\right)^{\mu_{i}^{j}} \text { and } X_{i, t}=\xi_{i, t} \prod_{j=1}^{J}\left(X_{i, t}^{j}\right)^{\chi_{i}^{j}},
$$

with $\mu_{i, t}^{j}, \chi_{i, t}^{j}>0$ and $\sum_{j=1}^{J} \mu_{i, t}^{j}=\sum_{j=1}^{J} \chi_{i, t}^{j}=1$ for all $i=1, \ldots, I$ and $t=0,1, \ldots$ Here, $\xi_{i, t}$ is an investment-specific efficiency shifter that we also allow to exogenously change over time. ${ }^{17}$

Regarding international borrowing and lending as well as capital accumulation, note that the dynamics in the household problem arise entirely through these two decisions. Here, $B_{i, t}$ is the stock of one-period bonds in terms of world currency units owned by country $i$ at the beginning of period $t$. In period $t=0$, these bonds exist in zero-net supply - that is, $\left\{R_{0} B_{i, 0}\right\}_{i=1}^{I}$ are given such that $\sum_{i} R_{0} B_{i, 0}=0$. Capital is non-tradable, so households rent it to domestic firms and must use domestic resources to invest and accumulate capital over time. Because of perfect competition, firms make no profits and behave statically. Hence, all endogenous dynamics occur through the household.

\subsection{Prices and Optimal Decisions}

\subsubsection{Firms: Trade Costs and Prices}

For each sector $j=1, \ldots, J$, goods $\omega^{j} \in[0,1]$ can be traded across countries but are subject to trade costs. Specifically, the cost of shipping any good $\omega^{j} \in[0,1]$ from country $h$ to country $i$ at time $t$ consists of iceberg-type trade barriers, $d_{i h, t}^{j} \geq 1$, and add valorem tariffs, $\kappa_{i h, t}^{j} \geq 0$. Hence, the total add valorem cost of shipping a good $\omega^{j} \in[0,1]$ from country $h$ to country $i$ at time $t$ is given by $\tau_{i h, t}^{j} \equiv d_{i h, t}^{j}\left(1+\kappa_{i h, t}^{j}\right) \geq 1$. These costs imply that, in order for one unit of variety $\omega^{j}$ to be available in country $i$ at time $t$, country $h$ must ship $d_{i h, t}^{j}$ units of the good. We assume that $\tau_{i i, t}^{j}=1$ for all $i=1, \ldots, I$ - that is, there are no trade costs associated with trading goods within countries. Note that these bilateral trade costs are allowed to change over time and that they are sector, but not good specific. Hence, we also allow exogenous changes in trade costs to trigger transitional dynamics in the model.

Let us now turn to the optimal decisions by firms. In particular, first consider the problem faced

\footnotetext{
${ }^{16}$ Note that we do not consider capital adjustment costs. This assumption is inconsequential for the comparison of steady states; however, such costs matter for the determination of transitional dynamics.

${ }^{17}$ This shifter will be very helpful when we take the model to the data in Section 4.
} 
by the producer of good $\omega^{j} \in[0,1]$. Assuming perfectly competitive markets ${ }^{18}$ and given constant returns to scale in the production of good $\omega^{j}$, the free-on-board price (before trade costs) of one unit of this good, if actually produced in country $i$ at time $t$, will be equal to its marginal cost, $\frac{c_{i, t}^{j}}{x_{i, t}^{j}\left(\omega^{j}\right)}$, where $c_{i, t}^{j}$ is the cost of the input bundle to produce one unit of $\omega^{j}$. This cost is given by

$$
c_{i, t}^{j}=\varkappa_{i}^{j}\left[\left(P_{i, t}^{V}\right)^{\nu_{i}^{j}}\left(\prod_{m=1}^{J}\left(P_{i, t}^{m}\right)^{\alpha_{i}^{j, m}}\right)^{1-\nu_{i}^{j}}\right]
$$

with

$$
P_{i, t}^{V}=\left[\gamma_{i}^{j}\left(w_{i, t}^{U}\right)^{1-\sigma}+\left(1-\gamma_{i}^{j}\right)\left(P_{i, t}^{Z}\right)^{1-\sigma}\right]^{\frac{1}{1-\sigma}}
$$

and

$$
P_{i, t}^{Z}=\left[\varphi_{i}^{j}\left(r_{i, t}\right)^{1-\rho}+\left(1-\varphi_{i}^{j}\right)\left(w_{i, t}^{S}\right)^{1-\rho}\right]^{\frac{1}{1-\rho}}
$$

where $\varkappa_{i}^{j}$ is a constant that depends on production parameters. ${ }^{19}$

For a particular sector $j$, note that the technologies to produce goods $\omega^{j} \in[0,1]$ differ only by their productivity draw, while $c_{i, t}^{j}$ is constant across tradable goods. Hence, we can relabel tradable goods by their efficiencies, $x_{i, t}^{j}$, and define $U_{i, t}^{j}, S_{i, t}^{j}, K_{i, t}^{j}$ and $D_{i, t}^{j, m}$ as total factor (unskilled labor, skilled labor and physical capital) usage in sector $j$ and intermediate input usage from each sector $m$ in sector $j .^{20}$

Regarding the problem faced by the non-tradable sectoral goods producers, given the price of each variety $\omega^{j} \in[0,1]$ that the representative firm is faced with, $p_{i, t}^{j}\left(\omega^{j}\right)$, the firm minimizes costs, resulting in demand functions, conditional on $Q_{i, t}^{j}$, for each tradable good $\omega^{j} \in[0,1]$ given by

\footnotetext{
${ }^{18}$ Following the standard quantitative trade literature, we assume perfect competition throughout the main text. The literature is geared toward a long-run view, where competition and entry may be less important for understanding the impacts of trade (see Arkolakis et al. (2018) for a full discussion). Nevertheless, if markets adjust slowly, evolving market structure may be important for transition dynamics (e.g., Amiti et al. (2019) found that tariffs were fully passed through to American consumers during 2018 US-China trade war). Thus, we see our baseline assumption as a shortcoming of the current framework, and an important avenue for future research.

${ }^{19}$ Specifically, $\left.\varkappa_{i}^{j}=\left(\nu_{i}^{j}\right)^{-\nu_{i}^{j}}\left(\left(1-\nu_{i}^{j}\right) \prod_{m=1}^{J}\left(\alpha_{i}^{j, k}\right)^{\alpha_{i}^{j, m}}\right)\right)^{-\left(1-\nu_{i}^{j}\right)}$.

${ }^{20}$ Letting $\varrho^{j}\left(x^{j} \mid t\right)$ denote the conditional joint density of the sector specific vector of productivity draws for all countries, $x^{j}=\left(x_{1, t}^{j}, \ldots, x_{I, t}^{j}\right)$, these variables are defined for $G \in\{U, S, K\}$ and $g \in\{u, s, k\}$ as

$$
F_{i, t}^{j}=\int_{\mathbb{R}_{+}^{I}} f_{i, t}^{j}\left(x^{j}\right) \varrho^{j}\left(x^{j} \mid t\right) \text { and } D_{i, t}^{j, m}=\int_{\mathbb{R}_{+}^{I}} D_{i, t}^{j, m}\left(x^{j}\right) \varrho^{j}\left(x^{j} \mid t\right) d x^{j} .
$$
}


$d_{i, t}^{j}\left(\omega^{j}\right)=\left(\frac{P_{i, t}^{j}}{p_{i, t}^{j}\left(\omega^{j}\right)}\right)^{\eta} Q_{i, t}^{j}$, where

$$
p_{i, t}^{j}\left(\omega^{j}\right)=\min _{h}\left\{p_{h, t}^{j}\left(\omega^{j}\right)\right\}=\min _{h}\left\{\frac{c_{h, t^{j}}^{j} \tau_{h, t}^{j}}{x_{h, t}^{j}\left(\omega^{j}\right)}\right\}
$$

and $P_{i, t}^{j}$ denotes the price of sectoral good $j$, which is given by

$$
P_{i, t}^{j} \equiv\left(\int_{0}^{1} p_{i, t}^{j}\left(\omega^{j}\right)^{1-\eta} d \omega^{j}\right)^{\frac{1}{1-\eta}}
$$

Note that firms, by minimizing their costs, source tradable good $\omega^{j}$ from the lowest-cost supplier after taking into account trade costs, as is implied by (13).

\subsubsection{Sectoral Gravity}

Given the efficiency distributions, we can derive an expression for sectoral price indices in equilibrium as functions of all sectoral prices, factor prices, and trade costs around the world. These prices are conditional on the known values of sectoral productivities, $T_{i, t}^{j}$, and bilateral trade costs, $\tau_{i h, t}^{j}$, in period $t$. Using (14) and the properties of the distribution of efficiencies around the world, we can derive the sectoral prices in each country $i$ and every period $t$. These prices are given by

$$
P_{i, t}^{j}=\Gamma^{j}\left[\Phi_{i, t}^{j}\right]^{-\frac{1}{\theta^{j}}}
$$

where $\Gamma^{j}$ is a constant that only depends on $\eta$ and $\theta^{j}$ and

$$
\Phi_{i, t}^{j}=\sum_{h=1}^{I} T_{h, t}^{j}\left(c_{h, t}^{j} \tau_{i h, t}^{j}\right)^{-\theta^{j}}
$$

represents a sufficient statistic for sector $j$ in country $i$ of the state of technologies and trade costs around the globe. ${ }^{21}$

The structure of the model not only allows for closed-form solutions of sectoral price indices, but also for recovering sectoral trade shares for each country in terms of world prices, technologies and trade costs - that is, we can find expressions for the share of total expenditure on goods produced in sector $j$ that is spent in each country. Let $E_{i, t}^{j}$ denote total expenditure by country $i$ on sector $j$

\footnotetext{
${ }^{21}$ In particular, $\Gamma^{j}=\left(\Gamma\left(1+\frac{(1-\eta)}{\theta^{j}}\right)\right)^{\frac{1}{1-\eta}}$, where $\Gamma(\cdot)$ denotes the Gamma function evaluated for $z>0$. Note that this equation implies that parameters have to be such that $\eta-1<\theta$.
} 
goods and $E_{i h, t}^{j}$ total expenditure by country $i$ on sector $j$ goods produced in country $h$, so that $E_{i, t}^{j}=\sum_{h=1}^{I} E_{i h, t}^{j}$. Then, the share of total expenditure in sector $j$ by country $i$ in goods produced by country $h, \pi_{i h, t}^{j} \equiv \frac{E_{i h, t}^{j}}{E_{i, t}^{j}}$, is given by

$$
\pi_{i h, t}^{j}=\frac{T_{h, t}^{j}\left(c_{h, t}^{j} \tau_{i h, t}^{j}\right)^{-\theta^{j}}}{\Phi_{i, t}^{j}}
$$

and is such that $\sum_{h=1}^{I} \pi_{i h, t}^{j}=1$ for all $i=1, \ldots, I$ and $j=1, \ldots, J$. Note that using the expression we obtained earlier for equilibrium prices, equation (15), we can rewrite this share in terms of the sectoral price in country $i$ as

$$
\pi_{i h, t}^{j}=\left(\Gamma^{j}\right)^{-\theta^{j}} T_{h, t}^{j}\left(\frac{c_{h, t}^{j} \tau_{i h, t}^{j}}{P_{i, t}^{j}}\right)^{-\theta^{j}}
$$

These prices and trade shares fully summarize the optimal decisions by the firms given technologies and factor prices, as well as bilateral trade flows given sectoral expenditure levels in all countries. This fact can be appreciated in (15), which implicitly defines sectoral prices as a function of factor prices, and (18), which defines all bilateral trade shares given these sectoral prices.

\subsubsection{Households: Investment and Savings}

Solving the problem for the household can be simplified by dividing it into two subproblems, a static subproblem and a dynamic one. Let us first consider the static subproblem that the household faces in period $t$ given choices for $B_{i, t+1}$ and $K_{i, t+1}$. Conditional on $C_{i, t}$, which is implied by the choices of $B_{i, t+1}$ and $K_{i, t+1}$, the household optimally chooses sectoral consumption expenditure across sectors according to $P_{i, t}^{j} C_{i, t}^{j}=\mu_{i, t}^{j} P_{i, t}^{C} C_{i, t}$, where $P_{i, t}^{C}$ denotes the ideal consumption price index given by $P_{i, t}^{C}=\varkappa_{i}^{C} \prod_{j=1}^{J}\left(P_{i, t}^{j}\right)^{\mu_{i, t}^{j}}$ such that total consumption expenditure is given by $E_{i, t}^{C} \equiv \sum_{j=1}^{J} P_{i, t}^{j} C_{i, t}^{j}=P_{i, t}^{C} C_{i, t}$ and where $\varkappa_{i}^{C}$ is a constant that depends on $\mu_{i}^{j}$.

Regarding investment, conditional on the choice of $X_{i, t}$, which is also pinned down by the choices of $B_{i, t+1}$ and $K_{i, t+1}$, the household optimally chooses sectoral investment levels across sectors according to $P_{i, t}^{j} X_{i, t}^{j}=\chi_{i, t}^{j} \frac{P_{i, t}^{X}}{\xi_{i, t}} X_{i, t}$, where $P_{i, t}^{X}$ denotes the ideal investment price index before adjusting by efficiency, which is given by $P_{i, t}^{X}=\varkappa_{i}^{X} \prod_{j=1}^{J}\left(P_{i, t}^{j}\right)^{\chi_{i, t}^{j}}$ such that total investment expenditure is given by $E_{i, t}^{X} \equiv \sum_{j=1}^{J} P_{i, t}^{j} X_{i, t}^{j}=\frac{P_{i, t}^{X}}{\xi_{i, t}} X_{i, t}$ and where $\varkappa_{i}^{X}$ is a constant that depends on $\chi_{i}^{j}$ 
Let us now turn to the dynamic subproblem - that is, the optimal determination of $C_{i, t}$ and $X_{i, t}$ implied by the optimal choices of $B_{i, t+1}$ and $K_{i, t+1}$ by the household in country $i$. The household in country $i$ takes its wealth at $t=0$ as given, composed of $W_{i, 0} \equiv R_{0} B_{i, 0}$ and $K_{i, 0}$, and chooses $\left\{C_{i, t}, X_{i, t}, K_{i, t+1}, B_{i, t+1}\right\}_{t=0}^{\infty}$ to maximize

$$
\sum_{t=0}^{\infty} \beta^{t} \ln \left(C_{i, t}\right)
$$

subject to the sequence of budget constraints and the law of motion for capital given by

$$
P_{i, t}^{C} C_{i, t}+\frac{P_{i, t}^{X}}{\xi_{i, t}} X_{i, t}+B_{i, t+1}+\frac{\psi}{2}\left(B_{i, t+1}-\bar{B}_{i}\right)^{2}=w_{i, t}^{U} U_{i, t}+w_{i, t}^{S} S_{i, t}+r_{i, t} K_{i, t}+R_{t} B_{i, t}+\mathcal{T}_{i, t}
$$

and

$$
K_{i, t+1}=X_{i, t}+(1-\delta) K_{i, t}
$$

respectively, for every $t=0, \ldots$.

The solution to the household's dynamic problem is characterized by a pair of Euler equations. First, the Euler equation corresponding to the optimal choice of bonds,

$$
\frac{P_{i, t+1}^{C} C_{i, t+1}}{P_{i, t}^{C} C_{i, t}}=\frac{\beta R_{t+1}}{1+\psi\left(B_{i, t+1}-\bar{B}_{i}\right)}
$$

The second Euler equation corresponds to optimal capital accumulation decisions and is given by

$$
\frac{R_{t+1}}{P_{i, t+1}^{X} / P_{i, t}^{X}} \frac{\xi_{i, t+1}}{\xi_{i, t}}=\frac{r_{i, t+1}}{P_{i, t+1}^{X} / \xi_{i, t+1}}+(1-\delta)
$$

In addition, the budget constraint and the law of motion for capital complete the set of equations that characterize the household's problem.

\subsection{Market Clearing Conditions}

Let $Y_{i, t}^{j}$ denote the value of gross production in sector $j$ and $E_{i, t}^{j}$ denote total expenditure by country $i$ on sector $j$ goods. Then, the value of total gross production and total expenditure net of tariffs in country $i$ and sector $j$ define sectoral net exports,

$$
N X_{i, t}^{j}=Y_{i, t}^{j}-\left(E_{i, t}^{j}-\sum_{h=1}^{I} \kappa_{i h, t} \frac{\pi_{i h, t}^{j} E_{i, t}^{j}}{1+\kappa_{i h, t}}\right)
$$


and aggregate net exports are then simply given by $N X_{i, t}=\sum_{j=1}^{J} N X_{i, t}^{j}$.

First, the markets for non-tradable sectoral goods and factors must clear in every country and period. These conditions are given by

$$
C_{i, t}^{j}+X_{i, t}^{j}+\sum_{k=1}^{J} D_{i, t}^{k, j}=Q_{i, t}^{j}
$$

for all $i$ and $j$, and $\sum_{j=1}^{J} U_{i, t}^{j}=U_{i, t}, \sum_{j=1}^{J} S_{i, t}^{j}=S_{i, t}$ and $\sum_{j=1}^{J} K_{i, t}^{j}=K_{i, t}$ for all $i$. Condition (25) states that demand for non-tradable goods must equal supply in each country $i$. We can reformulate this condition in terms of expenditures, in which case we can appreciate that total expenditure in goods in sector $j$ in equilibrium must be given by

$$
E_{i, t}^{j}=P_{i, t}^{j} C_{i, t}^{j}+P_{i, t}^{j} X_{i, t}^{j}+\sum_{m=1}^{J} P_{i, t}^{j} D_{i, t}^{m, j} .
$$

Thus, these equilibrium conditions can be rewritten simply as $E_{i, t}^{j}=P_{i, t}^{j} Q_{i, t}^{j}$.

We now turn to market clearing in tradable goods markets. In terms of expenditure, we refer to these conditions as the flow of goods across countries equilibrium conditions. These conditions are given by

$$
Y_{i, t}^{j}=\sum_{h=1}^{I} \frac{\pi_{h i, t}^{j} E_{h, t}^{j}}{1+\kappa_{h i, t}^{j}}
$$

and must hold for every country $i$ and sector $j$. This condition states that expenditure by all countries on sector $j$ goods produced in country $i$ must equal the value of total gross production in country $i$. In particular, country $h$ spends $\pi_{h i, t}^{j} E_{h, t}^{j}$ on sector $j$ goods produced in country $i$ inclusive of the tariff $\kappa_{h i, t}^{j}$. Thus, the actual expenditure in sector $j$ by country $h$ on goods produced in country $i$ that firms receive after tariffs is $\frac{\pi_{h i, t}^{j} E_{h, t}^{j}}{1+\kappa_{h i, t}^{j}}$.

Total tariff revenue in country $i$ is given by the sum of tariff revenues across sectors, $\mathcal{T}_{i, t}=$ $\sum_{j=1}^{J} \mathcal{T}_{i, t}^{j}$, where the revenue for sector $j$ of country $i$ is given by

$$
\mathcal{T}_{i, t}^{j}=\sum_{h=1}^{I} \kappa_{i h, t}^{j} \frac{\pi_{i h, t}^{j} E_{i, t}^{j}}{1+\kappa_{i h, t}^{j}} .
$$

Lastly, there are country-specific resource constraints, which are one of the main differences between a model with endogenous trade imbalances and static trade models. Net exports in goods and services must be consistent with optimal saving decisions by the representative household in 
country $i$. This equilibrium resource constraint is given by

$$
B_{i, t+1}-R_{t} B_{i, t}=\sum_{j=1}^{J} N X_{i, t}^{j}
$$

Another way to interpret this condition is through the balance of payments. This condition is equivalent to the balance of payments identity that is trivially satisfied in most international macroeconomic models and not present in static trade models. This identity can be appreciated by rewriting the previous condition as $N X_{i, t}+\left(R_{t}-1\right) B_{i, t}+B_{i, t}-B_{i, t+1}=0$, where $C A_{i, t} \equiv$ $N X_{i, t}+\left(R_{t}-1\right) B_{i, t}$ denotes the current account in country $i$ and $K A_{i, t} \equiv B_{i, t}-B_{i, t+1}$ denotes the broadly defined capital account.

\subsection{Steady-State Equilibrium}

We will use the model to compare steady-state outcomes for different configurations of trade barriers. ${ }^{22}$ Hence, we now turn to the characterization of the steady state of the model. Note that all equilibrium conditions of the model are static in nature except for the Euler equations. Therefore, we focus on these conditions.

For any variable $F_{i, t}^{j}$, let $F_{i}^{j}$ denote its steady-state value. In a steady-state equilibrium of the model, equation 22 implies that the distribution of net foreign assets is given by $\left\{\bar{B}_{i}\right\}_{i=1, \ldots, I}$ and current accounts are zero for all countries as long as $\psi>0$. In addition, capital stocks for all countries must be such that the two following conditions hold:

$$
\frac{r_{i}}{P_{i}^{X} / \xi_{i}}=\frac{1}{\beta}-(1-\delta) \text { and } \delta K_{i}=X_{i}
$$

The first equation in (30) is the Euler equation in steady state, where $R_{i}=1 / \beta$, while the second is derived from the law of motion for capital.

The first equation in (30) shows how higher trade costs leading to a higher price of investment goods result in a decrease in the real return to capital and, therefore, a decrease in investment, leading to a lower capital stock in a new steady state. However, note that such changes in trade costs can also have general equilibrium effects on the rental rate, $r_{i}$, through $\mathrm{HO}$ forces that could attenuate the direct effect of trade costs on investment prices.

\footnotetext{
${ }^{22}$ We focus on the case of trade barriers even though the model can be equally useful to examine the effects of changes in other types of parameters like productivities or efficiency shifters.
} 


\section{Taking the Model to the Data}

One of the key features of the model presented in Section 3 is that it clearly maps to data. In this section, we describe this mapping and the data we used to calibrate all parameters. ${ }^{23}$

The exogenous parameters of the model can be grouped into two categories: (i) time-invariant parameters and exogenous observable endowments and (ii) exogenous shifters. We assume that the world economy is in a steady state in 2016 and will choose values for the aforementioned objects of the model to match this steady state. The calibration of time-invariant parameters and exogenous observable endowments is described in Section 4.2. Exogenous shifters, which encompass trade barriers, productivities and investment efficiencies, are not directly observed in the data. In Section 4.3 we show how to recover these shifters by inverting our model. In this section, we reduce our sample to 30 countries and a rest of world (ROW) aggregate. We focus on 40 sectors - 20 of which are tradable and 20 of which are not. ${ }^{24}$ The group of 30 core countries considered consists of 20 AEs and 10 EMs and accounts for more than 85 per cent of world GDP and exports. We will consider the ROW block as another EM, making a total of 11 in our sample.

\subsection{Data}

We either collect or estimate data on (i) bilateral trade flows; (ii) sectoral gross output and value added; (iii) input-output tables; (iv) capital stocks and labor endowments of low- and high-skilled workers; (v) aggregate and sectoral compensations to capital, low- and high-skilled workers; (vi) aggregate GDP, consumption and investment; (vii) sectoral consumption and investment shares; and (viii) sectoral prices. ${ }^{25}$ Whenever possible, we collect these data for the year 2016 in order to consider it the benchmark year. However, certain data are not available for 2016, in which case we use the most recent data available. Details on the data and their sources are provided in Appendix A.

\footnotetext{
${ }^{23}$ The procedure follows closely that in Reyes-Heroles (2017).

${ }^{24}$ Non-tradable sectors in the model are simply those in which trade barriers across countries are set to infinity. The sets of countries and sectors we consider are described in Appendix A.

${ }^{25}$ Details on the data and estimation procedures are provided in Appendix A
} 


\subsection{Time-invariant Parameters and Exogenous Observable Endowments}

\subsubsection{Time-invariant Parameters}

We start by calibrating the time-invariant parameters of the model. Table 1 provides the parameter values considered, along with the sources used to choose their values. ${ }^{26}$

Table 1: Time-invariant Parameters

\begin{tabular}{ccll}
\hline \hline Parameter & Value & \multicolumn{1}{c}{ Variable } & \multicolumn{1}{c}{ Source } \\
\hline$\nu_{i}^{j}$ & - & Value added to gross output ratio & Data: OECD Stan, WIOD (SEA), UNs' INDSTAT2 and the NAs \\
$\alpha_{i}^{j, k}$ & - & Input-output coefficients & Data: WIOD 2016 release and OECD \\
$\gamma_{i}^{j}, \varphi_{i}^{j}$ & - & Factor shares in value added & Data: WIOD 2012 release and model \\
$\theta^{j}$ & - & Trade elasticities & Caliendo and Parro (2015) \\
$\sigma, \rho$ & - & Elasticities of substitution across factors & Parro (2013) \\
$\eta$ & 2 & Elasticity of substitution in tradable goods & Standard in literature \\
$\beta$ & 0.95 & Discount factor & In line with annual data \\
$\delta$ & 0.05 & Depreciation rate & In line with annual data \\
$\mu_{i}^{j}$ & - & Sectoral consumption expenditure shares & Data: WIOD 2016 release \\
$\chi_{i}^{j}$ & - & Sectoral investment expenditure shares & Data: WIOD 2016 release \\
\hline \hline
\end{tabular}

We compute the value added to gross output ratios and input-output coefficients directly from the data. To back out factor shares in value added, we rely on data for sectoral factors of production, factor prices and the optimality conditions derived by the firms in the model. Factor prices are obtained as the ratio of total compensation to a particular factor divided by its total endowment. We consider the same values of elasticities of substitution across factors of production as Parro (2013) and the same values for trade elasticities as Caliendo and Parro (2015). The values we consider for parameters $\eta, \beta$ and $\delta$ are standard in the literature. Sectoral consumption and investment shares are computed directly from data provided in the World Input-Output Database 2014 release.

A key channel through which the negative output effects of higher trade barriers can be amplified over time is if final investment is tilted toward sectors that are traded more intensively. ${ }^{27}$ If this is the case, increases in tariffs would disproportionately affect investment relative to consumption, given that the relative price of final investment would increase. Figure 8 shows the average sectoral consumption and investment shares across countries for tradable sectors. The figure also plots the average share of expenditure in each sector coming from foreign goods (indicated by the plus signs). Two patterns stand out. First, consumption goods and investment goods are different. Second, investment goods have slightly higher foreign expenditure shares on average. ${ }^{28}$ These findings are preliminary evidence that the investment channel may indeed be important.

\footnotetext{
${ }^{26}$ The parameter $\psi$ is not included in the table because this parameter is irrelevant in the steady state of the model.

${ }^{27}$ See Bussière et al. (2013) for other work related to this issue.

${ }^{28}$ Regressing the difference in sectoral shares, $\Delta y_{i}^{j}=\chi_{i}^{j}-\mu_{i}^{j}$ on the foreign trade share, $x_{i}^{j}=1-\pi_{i i}^{j}$, and controlling for country fixed effects, yields a statistically significant positive (0.03) coefficient on the foreign trade share.
} 
Figure 8: Investment and Consumption Sectoral Shares in Tradable Sectors

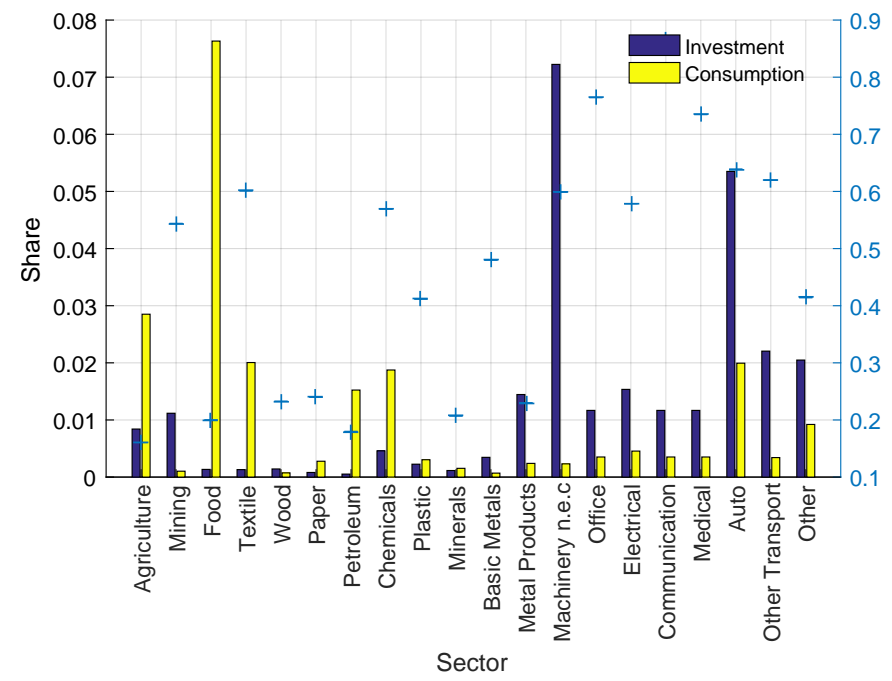

\subsubsection{Exogenous Observable Endowments}

Exogenous observable endowments are given by skilled and unskilled labor $\left(U_{i, t}\right.$ and $\left.S_{i, t}\right)$ as well as capital $\left(K_{i, t}\right)$. Labor endowments are directly observed in the data at a particular point in time. We recover the capital stock by recovering the level consistent with observed investment taking place in steady state. Note that differences in factor endowments across countries would lead to trade, in the spirit of $\mathrm{HO}$, even without productivity differences across space.

\subsection{Exogenous Shifters}

Given values for time-invariant parameters and exogenous observable endowments, we can recover exogenous unobservable shifters. In particular, we recover trade barriers, productivities and investment efficiencies, given by $\left\{\tau_{i h, t}^{j}, T_{i, t}^{j}, \xi_{i, t}\right\}$ for a given year $t=2016$.

It is important to discuss and emphasize how our calibrated model fits the data. We exploit the sector-specific gravity structure of the model to recover trade barriers and productivities consistent with bilateral trade shares. This approach allows us to perfectly match bilateral trade shares in each sector. Moreover, we calibrate sectoral consumption and investment shares to perfectly match the data. These two features of our calibration imply that the model perfectly replicates bilateral trade flows in the data and, therefore, facts 1 through 5 of Section 2. However, the model does not perfectly match fact 6 because it does not incorporate a global input-output table. ${ }^{29}$ Hence, our

\footnotetext{
${ }^{29}$ Given that the model matches the production structure, trade flows, and factor supplies, it delivers measures of factor content of trade that are in line with measures computed without adjusting for trade in inputs.
} 
calibration procedure implies that the model is able to replicate the data in 2016, and therefore most of our facts as well, as an equilibrium outcome in a steady state.

\subsubsection{Trade Barriers}

We recover trade barriers by exploiting the multi-sector gravity structure of the model. In particular, to recover $\tau_{i h, t}^{j}$, we consider the ratio of $\pi_{h h, t}^{j}$ to $\pi_{i h, t}^{j}$, both given in (17). Given values for trade elasticities, this ratio identifies $\tau_{i h, t}^{j}$ as a function of data only-bilateral trade shares and relative sectoral prices.

Figures 9 and 10 summarize our calibrated trade costs. Figures 9a and 9b show the median and 25 to 75 percentile ranges of bilateral importing and exporting trade costs for each country. The average median bilateral importing (exporting) trade cost is 134 (135.13) percent of sales prices. Moreover, EMs (blue bars) face higher average exporting and importing costs than AEs (red bars).

Figure 9: Trade Costs Across Countries: Median and 25th-75th percentile ranges

(a) Exporting Costs

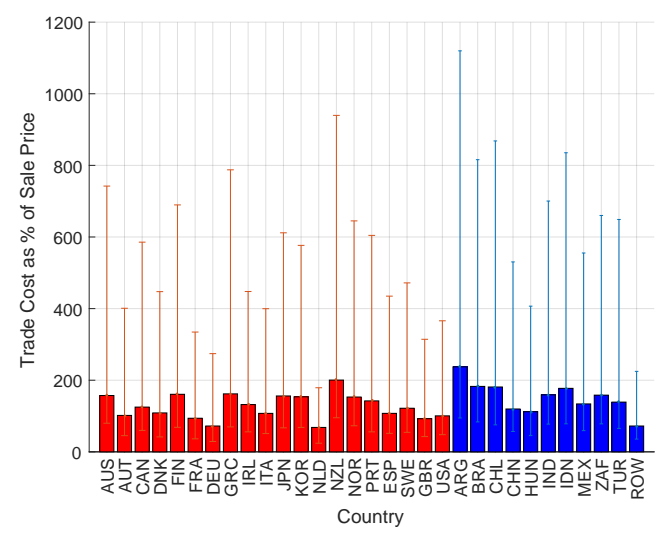

(b) Importing Costs

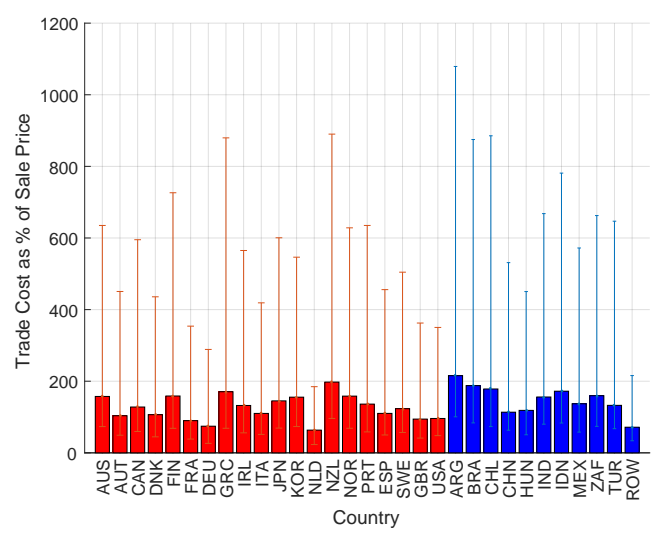

Averaging across sectors obscures some important differences. To show this issue, figure 10 plots median and 25 to 75 percentile ranges for trade costs in each tradable sector. The grouping is due to the differences in the y-axis needed to make the bars visible. In particular, food, petroleum, plastic, minerals and machines face trade costs that are an order of magnitude higher than those facing other sectors. Very high bilateral trade costs reflect sectors in which, given small differences in relative prices across country pairs, bilateral trade flows remain fairly small. Thus, this fact has to be explained by high trade barriers. 
Figure 10: Sectoral Trade Costs: Median and 25th-75th percentile ranges

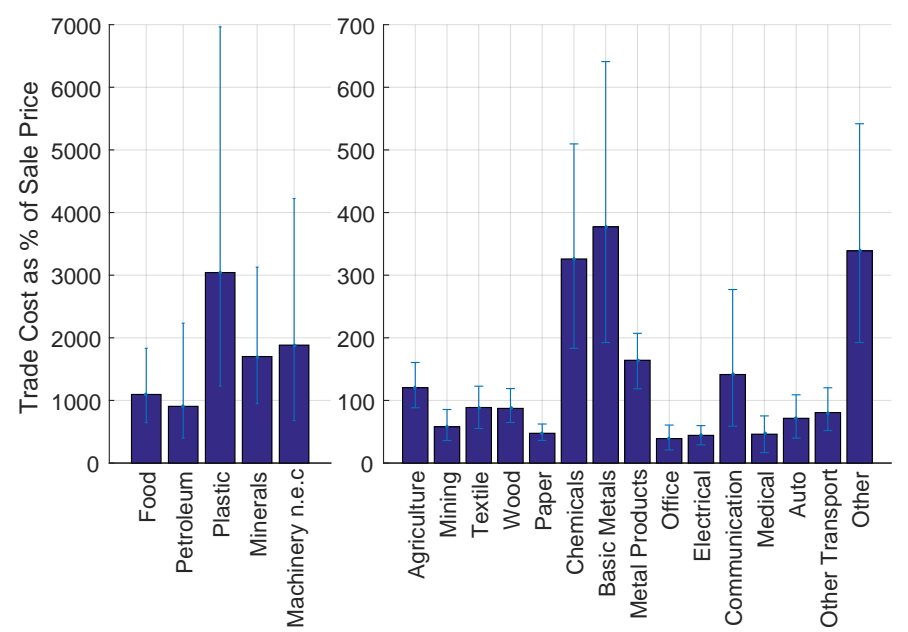

\subsubsection{Sectoral Productivities}

To recover sectoral productivities, we rely on the expression for equilibrium trade shares given in (18). Note that from this expression we obtain that, for any given country $i$, productivity in sector $j$ is $T_{i}^{j}=\pi_{i i, t}^{j}\left(\Gamma^{-\theta}\right)\left(c_{i, t}^{j} / P_{i, t}^{j}\right)^{\theta^{j}}$, where all terms in the right-hand side of the equality are data. Figure 11 shows the logarithm of adjusted sectoral productivities, $\left(T_{i}^{j}\right)^{\theta^{j}}$, relative to the United States.

Note that according to figure 11a, productivities in EMs (blue bars) are, on average, significantly lower than in the United States and other AEs (red bars). Our estimates imply that the United States represents the technological frontier - at least relative to the median sectoral productivity in each country. However, note that the 75 th percentile productivity being above zero for multiple AEs implies that these countries represent the technological frontier in certain sectors.

\subsubsection{Investment Efficiencies}

Investment efficiency shifters help us pin down the model to a steady state in a particular year. However, these shifters do not matter for the configuration of trade across countries. To recover investment efficiencies, we assume that the model is in a steady state in 2016 and use data on investment rates - that is, investment as a share of GDP. The law of motion for capital in a steady state implies that $X_{i}=\delta K_{i}$. Hence, given investment expenditures in 2016, we can recover the capital stock that is consistent with the former condition and solve the model. We pin down investment efficiencies such that the steady-state Euler equation for capital, condition (30), holds. 
Figure 11: Sectoral Productivities: Median and 25-75 percentile ranges, relative to the United States

(a) Productivities in Tradable Sectors

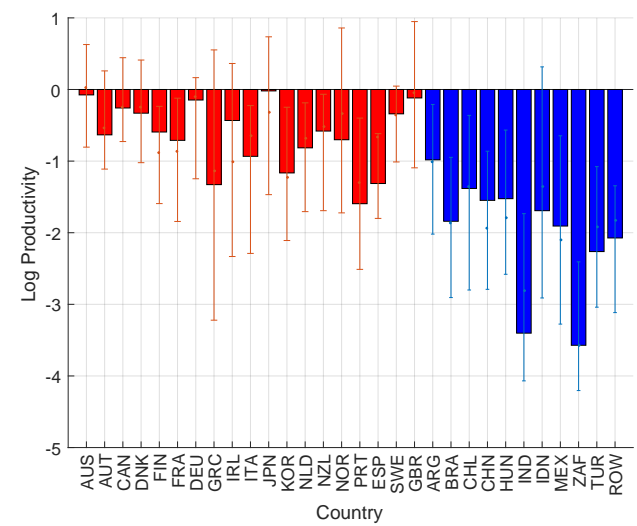

(b) Productivities in Non-tradable Sectors

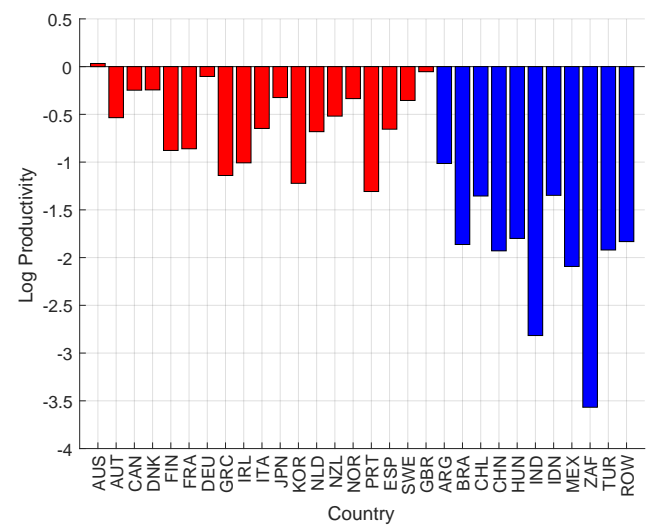

\section{The Effects of Rising Trade Barriers on Emerging Markets}

We use the calibrated model to conduct three counterfactual experiments and analyze the effects of rising trade barriers on EMs. First, we consider a 5 percentage point increase in tariffs. This simple exercise allows us to highlight the features of the model. Next, we study two important recent protectionist developments. The first is a 'no trade deal' Brexit scenario in which bilateral tariffs between the United Kingdom and European Union members increase from zero to Most Favored Nation (MFN tariffs). The second estimates the impact of the tariff increases between the United States and China since the beginning of 2018.

Each counterfactual experiment considers exogenous changes in trade barriers in isolation. Thus, we leave baseline sectoral productivities, investment shifters and endowments of skilled and unskilled labor unchanged. However, the model can be used to study exogenous change to these variables as well. For each counterfactual configuration of trade barriers, we solve the model for the steady-state equilibrium wages and rental rates such that labor and capital markets clear. Then we compute several outcomes of interest. In particular, we will focus on macroeconomic outcomes that include changes in GDP, welfare, relative factor prices and aggregate trade flows. Note that we compare steady states in all counterfactuals. Therefore, we are essentially analyzing the effects of permanent increases in tariffs. We provide some evidence supporting this assumption in the last two counterfactual exercises. In the last section of the paper, we discuss transition dynamics. 


\subsection{Global Increase in Tariffs}

Our first counterfactual exercise studies the effects of a global increase in trade barriers. Specifically, we consider a tariff increase of 5 percentage points for all bilateral trade. Even though we do not think this outcome is likely because of the widespread and permanent nature of the increase, we choose this scenario as a way to first illustrate the mechanisms of our international trade model and highlight the effects on all countries. The macroeconomic consequences of a global trade war are presented in Figure 12.

The global increase in trade barriers generates efficiency losses that lead to a sizable drop in output around the world. In the new steady state, world GDP is 1.6 percent below its initial steady-state value. Moreover, even though higher trade barriers generate GDP losses in the absence of changes in capital, a sizable share of these losses arises because of adjustments in the new steadystate level of capital. Of the overall drop in output, more than half - 0.9 percentage point - is driven by this endogenous adjustment, which is absent in static models. The macroeconomic elements of our model play a key role in shaping our results in the long run. As previously discussed, the increase in trade barriers has a first-order effect on the price of final investment, $P_{i}^{X}$, leading to a decline in the real return to capital, $r_{i} / P_{i}^{X}$. Therefore, investment decreases, leading to a decline in physical capital that drives the return on capital up until the steady-state condition, equation (30), is restored.

Figure 12a shows the percent change in GDP by country, where we split the group of countries into AEs and EMEs. The first result to point out is that, even though the increase in trade barriers is homogeneous across countries, its effects on GDP are heterogeneous. Moreover, the heterogeneity of these effects is greater within EMs, as can be seen from the yellow bars. For instance, the GDP of some EMs like Hungary and Mexico decreases by more than 4 percent, while the output of other larger economies like China remains almost unchanged. While the coefficient of variation of changes in AEs' GDP is 0.24, it is more than twice as large for EMs (0.6). Interestingly, GDP drops by similar amounts, 1.7 and 1.5 percent in AEs and EMs, respectively.

Ultimately, our analysis should focus on changes in welfare rather than output. Figure 12b shows the effects on consumption-which perfectly reflect changes in welfare without incorporating transitional dynamics-across countries. Note that welfare losses are similar in magnitude to GDP losses; however, the former are primarily driven by the increase in trade barriers absent an adjustment in investment. This difference reflects how the decline in investment triggered by the increase in 
trade costs generates larger drops in output than in consumption as investment decreases. The macroeconomic elements of the model play a key role in driving this result. Ultimately, real investment declines not only because it becomes more expensive, but also because it adjusts endogenously to dampen the effects of higher trade barriers on consumption and therefore welfare.

Even though the increase in tariffs affects all countries and sectors symmetrically, the increase in tariffs leads to an increase in the price of investment relative to consumption goods, as shown in figure 12c. This increase reflects the fact that tradable sectors play a disproportionate role in final investment relative to final consumption goods. The increase in the relative price amplifies the drop in investment that would be obtained if the prices of final consumption and investment were the same. This mechanism drives a key and sizable channel through which increases in trade barriers affect economic activity in the long run. As in the case of GDP, the effects of higher trade costs on the relative price of investment are more heterogeneous across EMs than AEs.

The effects of trade shocks on different types of workers has become the subject of an extensive literature in recent years. ${ }^{30}$ Our model can also speak to inequality across worker types depending on their level of skill. In particular, higher trade barriers can affect the returns to different skills unevenly. Figure 12d shows how uneven these effects can be even when the trade shock is symmetric across countries. Most of the countries experience a decline in their wage premium consistent with technologies featuring capital-skill complementarity and the decline in investment generated by higher trade barriers. However, there are a few exceptions like Greece, China and India, which are countries that exhibit relatively small increases in the relative price of investment. This result points in the direction of final investment in certain EMs being less exposed to import-intensive sectors.

Let us now turn to the effects on trade flows. The increase in trade barriers leads to a decline in exports as a share of world GDP of 2.0 percentage points (19.2 to 17.2 percent). The decline in world exports is unevenly distributed across sectors. Figure 12e shows that the effects on total exports are concentrated in sectors generally associated with low trade costs like agriculture, mining and auto, which reflects the non-linear nature of the effects of changes in trade costs on exports. Higher trade barriers also lead to a redistribution of world exports across AEs and EMs. Figure $12 \mathrm{f}$ shows how EMs' role in exports increases. In particular, EMs' share in world exports increases by 1.1 percentage points. Moreover, this increase is explained entirely by an increase in inter-group trade - exports from EMs to AEs - of close to 3 percentage points. Given that changes in GDP for both country groups is similar, the increase in exports from EMs to AEs must be driven either

\footnotetext{
${ }^{30}$ See, for example, Burstein and Vogel (2017), Burstein et al. (2019) and Cravino and Sotelo (2019)
} 
by asymmetries in initial trade barriers or by the relationship between comparative advantage and trade elasticities.

The results of our experiment shed light on how increasing trade barriers around the world would affect EMs. The increase in barriers would have sizable negative effects on global output and welfare, but EMs would be disproportionately affected. The effects on EMs are more heterogeneous, thus reflecting these economies' higher exposure to trade and the fact that they are not alike in terms of trade. Approximately half of the negative effects on output are driven by endogenous responses in investment to lower returns to capital, which reflects the exposure to trade-intensive sectors. Moreover, this channel seems to play a key role in the decline in welfare in EMs. Higher trade barriers lead to a redistribution of world exports toward EMs that ameliorate the welfare losses for these economies.

\subsection{Brexit}

On January 31, 2020, the United Kingdom officially left the European Union. Both parties entered a transition period to finalize detailed negotiations on their future relationship by the end of $2020 .^{31}$ In this scenario, we estimate the impact of a 'no trade deal' Brexit, where the United Kingdom imposes MFN tariffs on all EU members and vice versa.

To analyze the effects of a 'no trade deal' Brexit, we use the MFN database for 2016 and assume the EU's MFN rates would apply to bilateral trade. The macroeconomic consequences are presented in Figure 13.

Figure 13a shows how the negative effects of increasing trade costs are concentrated in the United Kingdom and Ireland. We find that the United Kingdom's GDP would fall by almost 0.2 percent. Interestingly, we find slightly more negative effects on Ireland, whose economy is estimated to lose almost 0.25 percent. As Figure 13c highlights, the relative price of capital surges for Ireland, which in turn depresses investment there. This outcome highlights Ireland's dependence on intermediate goods imports from the United Kingdom used for Irish investment. More broadly, it underscores the importance of including investment in international trade models to assess the impact of tariff increases.

We find that the negative GDP effects are concentrated in other EU countries. The EU members

\footnotetext{
${ }^{31}$ These negations will cover a U.K.-EU trade deal but given the short negotiation period and the United Kingdom's stated unwillingness to extend the transition period, there is a significant risk that the United Kingdom may leave the EU without a trade deal in place at the beginning of 2021. If this scenario materializes, trade between both parties would no longer be subject to zero tariffs but rather would increase to WTO tariffs.
} 
Figure 12: Global Increase in Tariffs: Macroeconomic Effects

(a) Gross Domestic Product

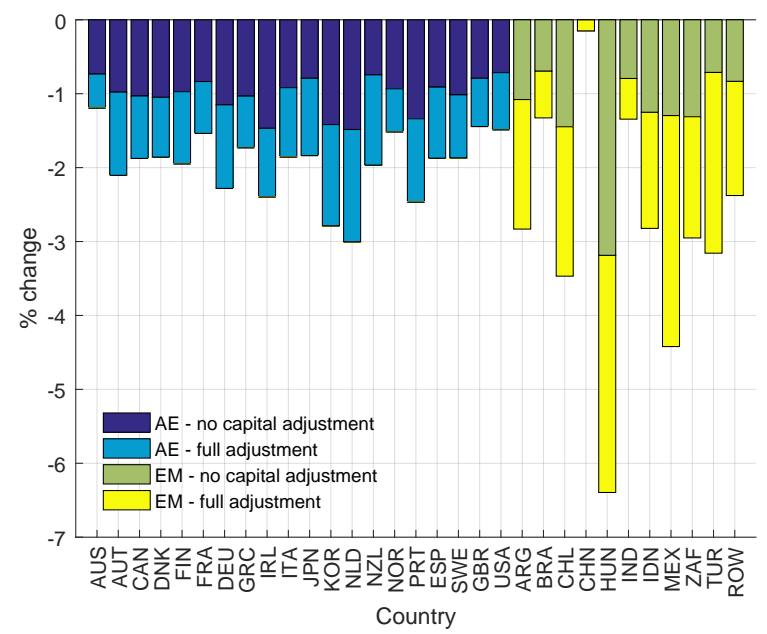

(c) Relative Price of Investment: $P_{i}^{X} / P_{i}^{C}$

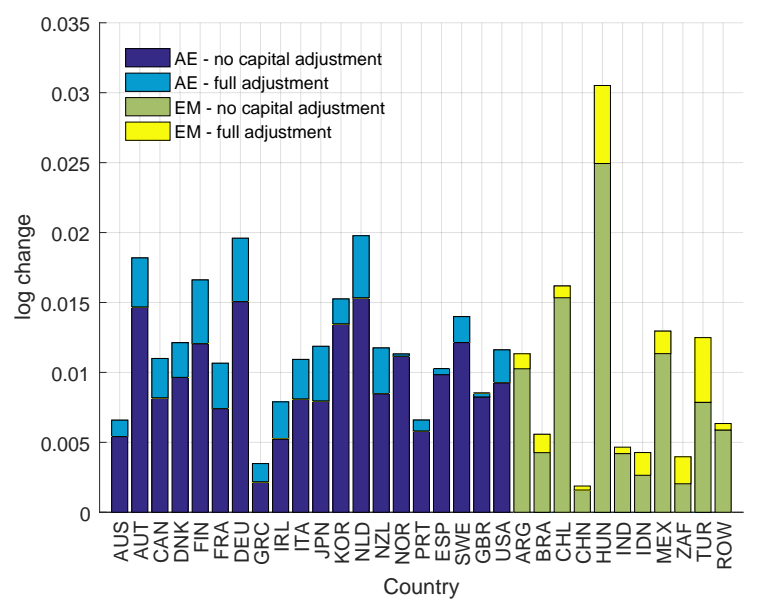

(e) World Exports by Sector

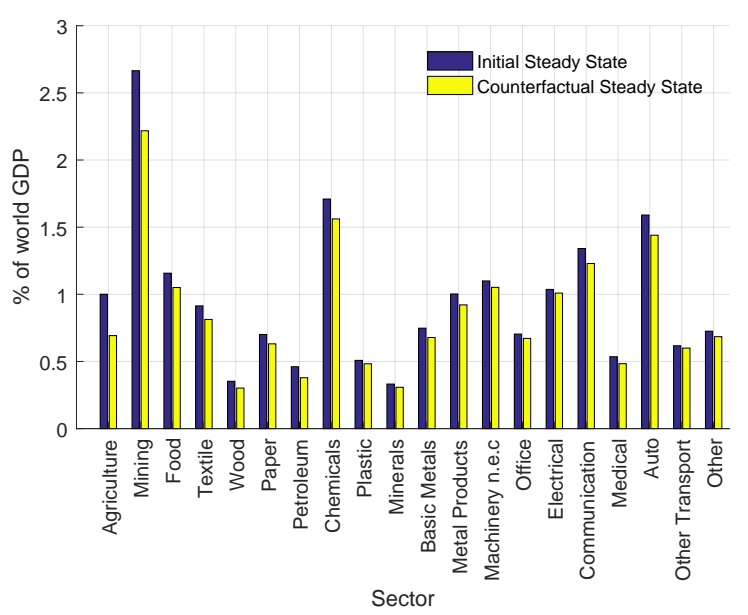

(b) Consumption

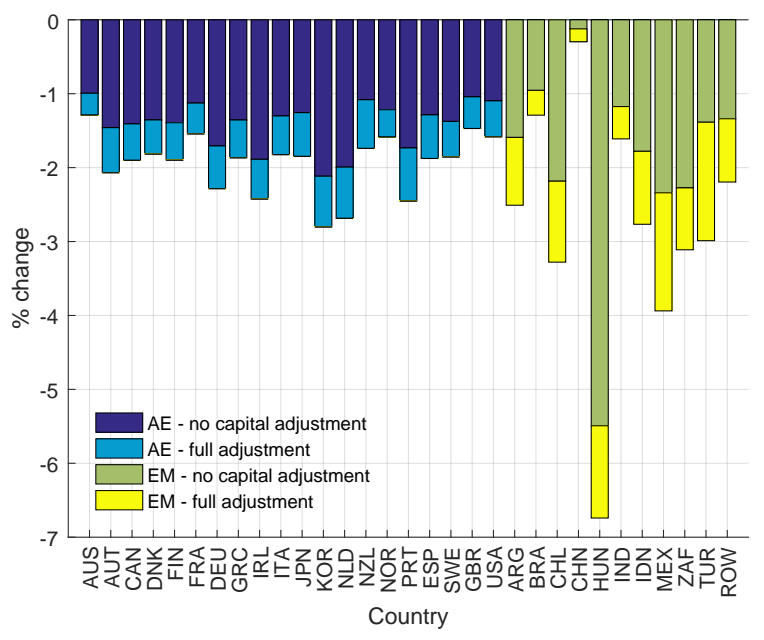

(d) Skill Premium: $w_{i}^{S} / w_{i}^{U}$

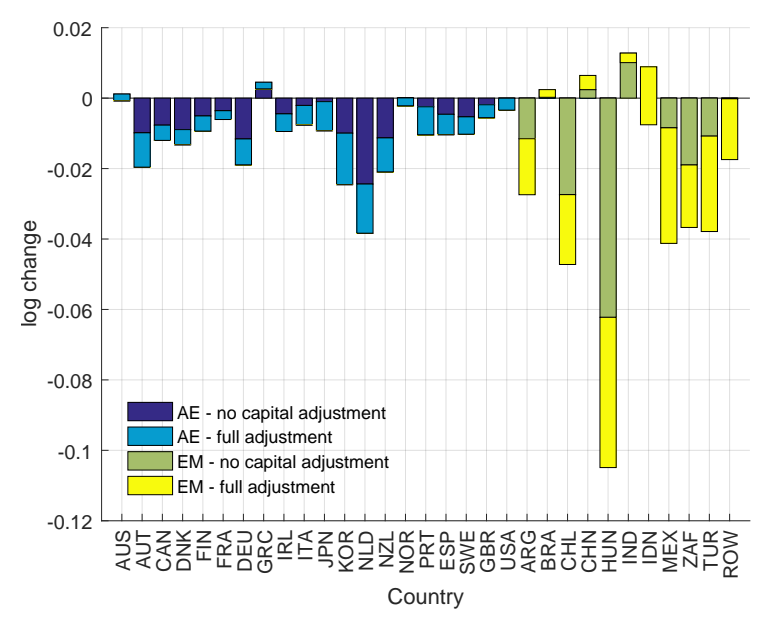

(f) Regional Exports

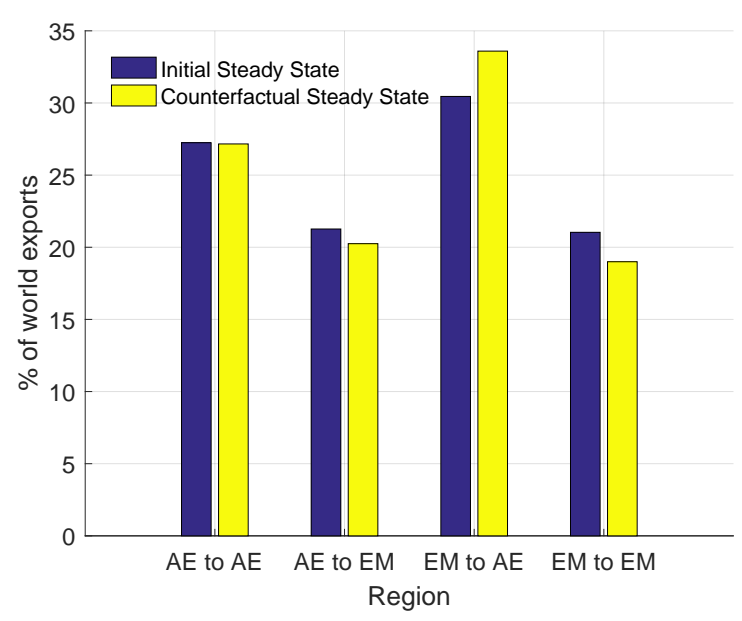


that experience the largest decreases are Hungary, the Netherlands and Denmark, as they are the countries that rely most on trade with the United Kingdom. ${ }^{32}$ In contrast, we find very little impact on EMs outside of the EU. That said, the results show that China stands to benefit from a 'no-trade deal' Brexit as the United Kingdom and the EU divert trade away from each other to China. Similarly, Turkey, who is not an EU member but is a large trading partner of the United Kingdom, is also estimated to gain from trade diversion.

Turning to consumption, shown in Figure 13b, we find effects that are similar in magnitude to the GDP results. Consumption in the United Kingdom and Ireland decrease by 0.17 and 0.24 percent, respectively. We find negative consumption results for AEs and EMs that are EU members, with the largest negative effects for Denmark, the Netherlands, and Hungary.

Finally, we find that world exports as a share of world GDP are almost unchanged. Similarly, as Figure 13f shows, trade among AEs and EMs is nearly unchanged.

All told, we find that the negative spillovers for EMs from a 'no trade deal' Brexit are limited. Only two EMs in our sample experience sizable spillovers. Hungary experiences significant declines in output and consumption driven by its proximity to the United Kingdom and sizable bilateral trade flows. At the other extreme is China, which experiences positive spillovers as it captures market share from AEs by increasing exports to these economies.

\subsection{The 2018-2020 Tariff Increases between China and the United States}

In this section, we estimate the effects of the increases in tariffs between China and the United States since the beginning of 2018. As of the bilateral phase One agreement in early 2020, the United States has raised tariffs on about $\$ 335$ billion of Chinese goods and China has raised tariffs on about $\$ 120$ billion of U.S. goods. Moreover, even though this agreement halved tariffs on a portion of bilateral trade, it only represents about 30 percent of bilateral trade subject to tariffs. ${ }^{33}$ The remaining 70 percent of bilateral trade is still subject to a tariff of about 25 percent. Furthermore, there have been no reported negotiations on a phase two agreement, suggesting that the tariff increases will likely remain in place for a long time. To analyze the effects of the bilateral tariff increases, we compile the tariff lists from the United States International Trade Commission (USITC) and the

\footnotetext{
${ }^{32}$ For example, in 2016, imports and exports by the Netherlands from and to the United Kingdom represented about 3 and 6 percent of Dutch GDP, respectively. As a comparison, for Germany, imports and exports from and to the United Kingdom represented about 1 and 2.7 percent of German GDP, respectively

${ }^{33}$ As part of the Phase one trade agreement, which went into effect on February 14 of 2020, the United States halved its tariff rate increase from 15 to 7.5 percent on about $\$ 100$ billion of Chinese goods. China reduced its tariff rate increase from 10 to 5 percent and from 5 to 2.5 percent on about $\$ 30$ billion of U.S. goods.
} 
Figure 13: 'No Trade Deal' Brexit: Macroeconomic Effects

(a) Gross Domestic Product

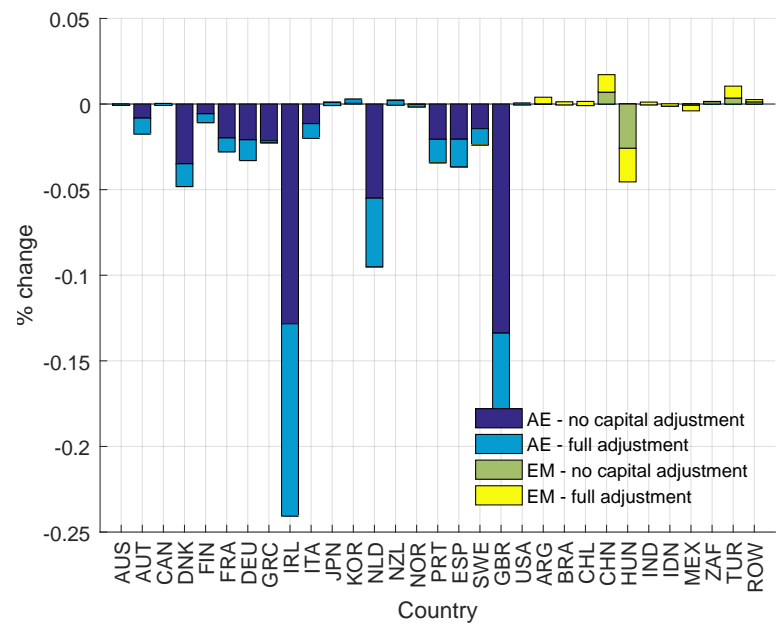

(c) Relative Price of Investment: $P_{i}^{X} / P_{i}^{C}$

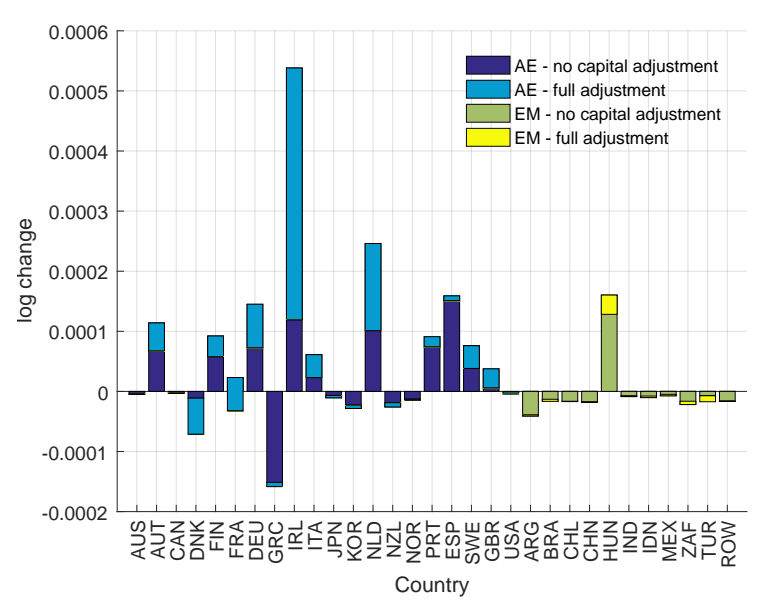

(e) World Exports by Sector

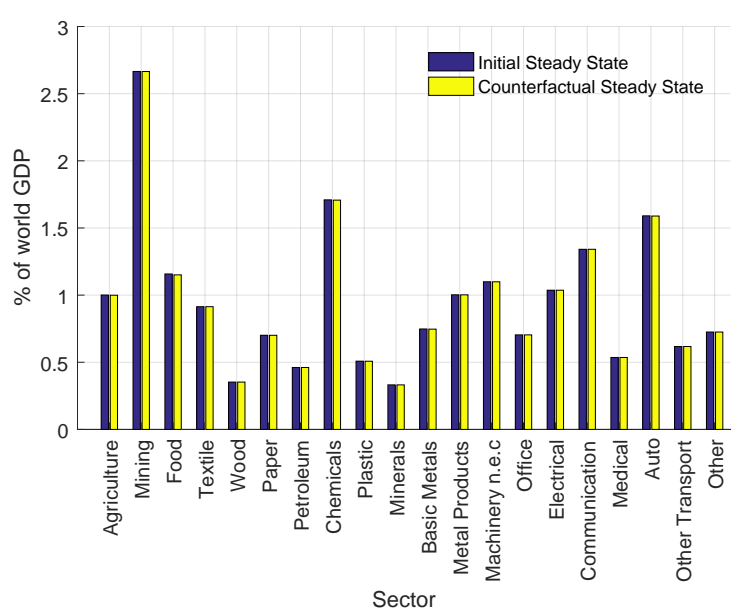

(b) Consumption

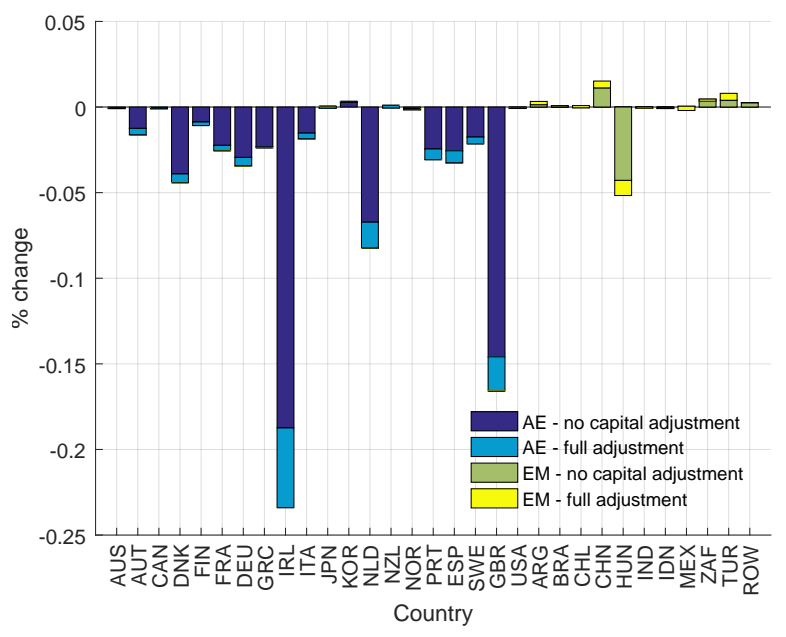

(d) Skill Premium: $w_{i}^{S} / w_{i}^{U}$

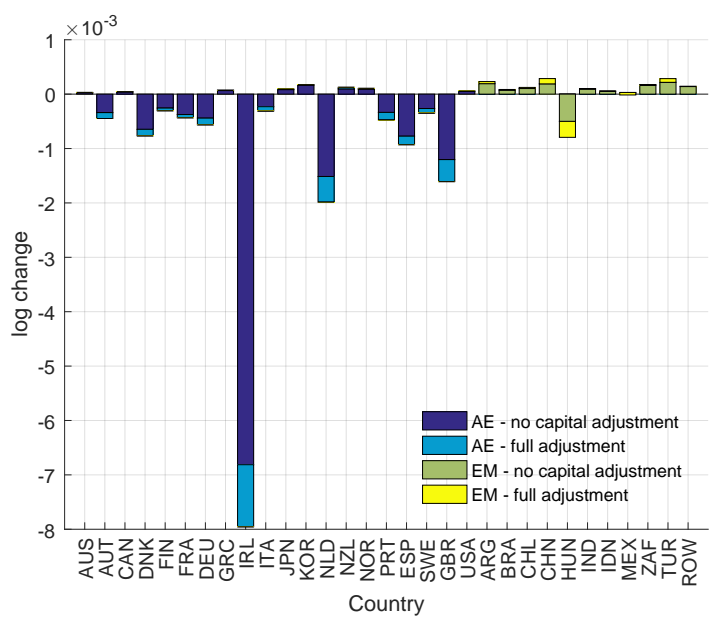

(f) Regional Exports

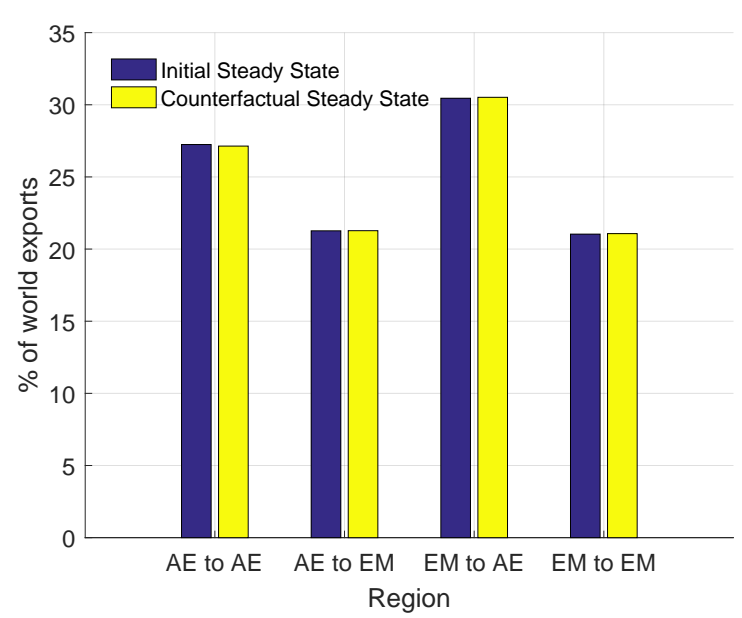


Ministry of Commerce in China (MOFCOM). ${ }^{34}$

The macroeconomic consequences of the increase in implemented tariffs between the United States and China are shown in figure 14.

Figure 14a shows that the implemented tariffs between the United States and China are estimated to lower world GDP by 0.3 percent and that half of the decline is driven by a drop in investment and capital stocks. The United States and China both experience a decline in GDP, of 1.3 and 0.9 percent, respectively. Interestingly, these results imply that the United States would suffer larger losses. As Figure 14c highlights, the relative price of capital surges for the United States, even in the absence of capital adjustments, which in turn depresses U.S. investment. This finding underscores the crucial role China plays in exporting intermediate goods used for U.S. investment and capital-intensive goods to the United States. ${ }^{35}$

Higher tariffs between the United States and China also have a quantitatively important impact on the rest of the world. Figure 14a highlights that these spillover effects are broadly positive for both AEs and EMs, but EMs tend to benefit more. Specifically, we find large positive spillover effects for countries like Mexico and Hungary, as they are estimated to benefit from trade diversion. Among the AEs, the results show that Japan and Korea are the largest beneficiaries, which is consistent with shifts in Asian supply chains away from Chinese suppliers. That said, these clear positive spillover effects do not compensate for the overall negative losses in GDP in the United States and China.

Regarding consumption, Figure 14a shows effects similar to those found for GDP. We find significant declines in consumption for both the United States and China, but larger losses for the former. The effects on consumption for the AEs excluding the United States are overall relatively small, with the exceptions of Japan and Korea. For the EMs excluding China, we find larger positive consumption effects, especially for Mexico and Hungary.

Finally, we find that world exports as a share of world GDP are almost unchanged, as they only edge up 0.01 percentage point. Moreover, Figure 14f shows that, in total, even though world exports are unchanged, there is a slight increase of 0.8 percentage point in intra-group trade.

Given our focus on the impacts of trade policy, it is worth asking if tariffs are ever optimal in our present setting. Given that the model is competitive, a global social planner would always wish to set $\tau=0$. If iceberg trade costs cannot be changed, the problem will nevertheless be constrained

\footnotetext{
${ }^{34}$ See Appendix A for more detail on the construction of the implemented tariffs.

${ }^{35}$ Recent work by Flaaen and Pirce (2019) shows that the U.S. tariffs are associated with relative reductions in manufacturing employment and relative increases in producer prices through rising input costs.
} 
Figure 14: 2018-19 Tariff Increases: Macroeconomic Effects

(a) Gross Domestic Product

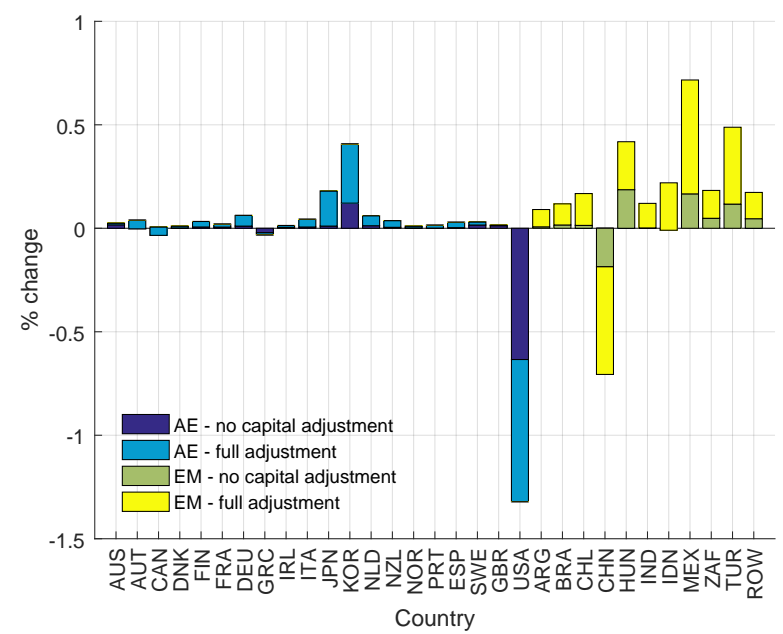

(c) Relative Price of Investment: $P_{i}^{X} / P_{i}^{C}$

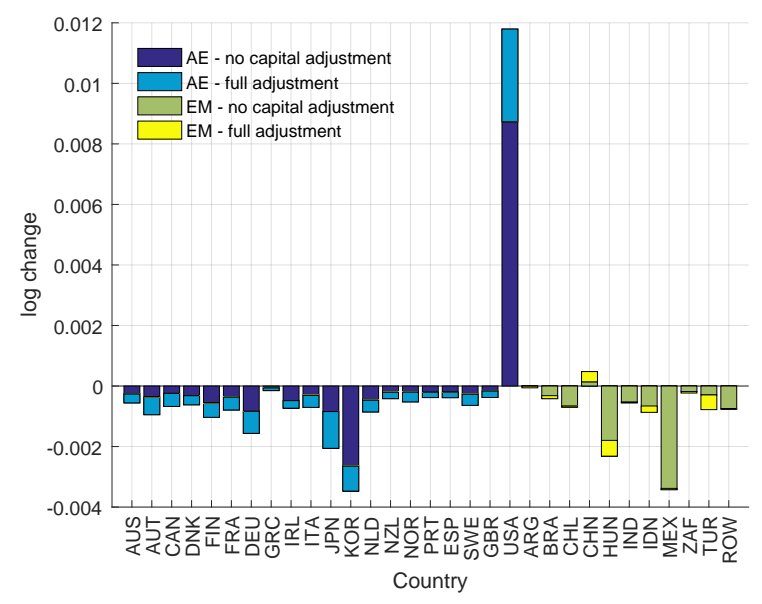

(e) World Exports by Sector

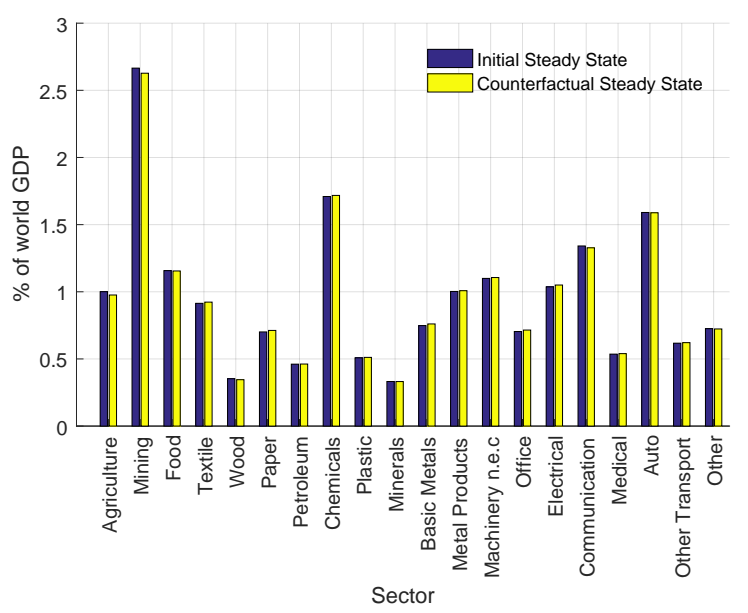

(b) Consumption

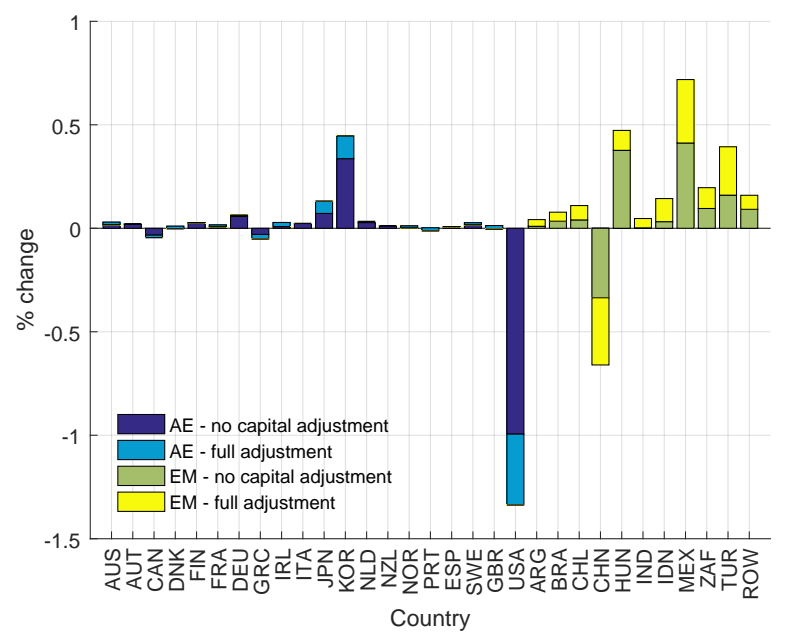

(d) Skill Premium: $w_{i}^{S} / w_{i}^{U}$

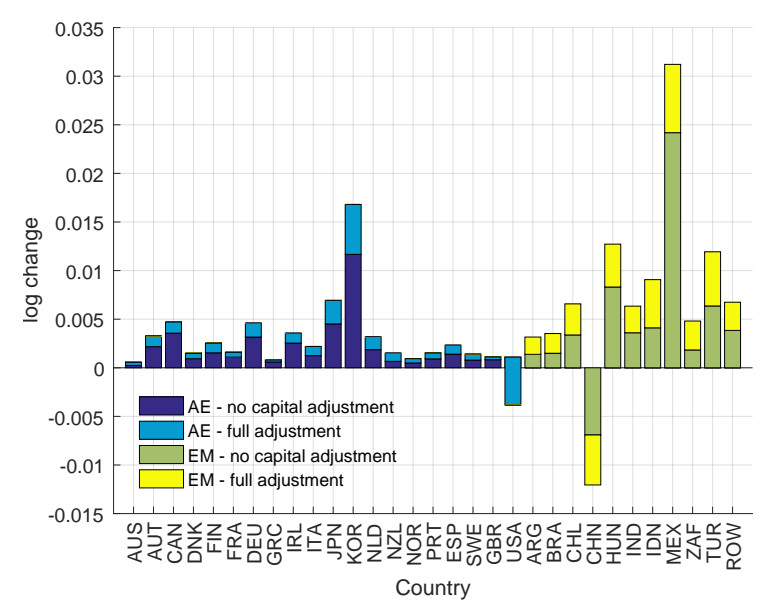

(f) Regional Exports

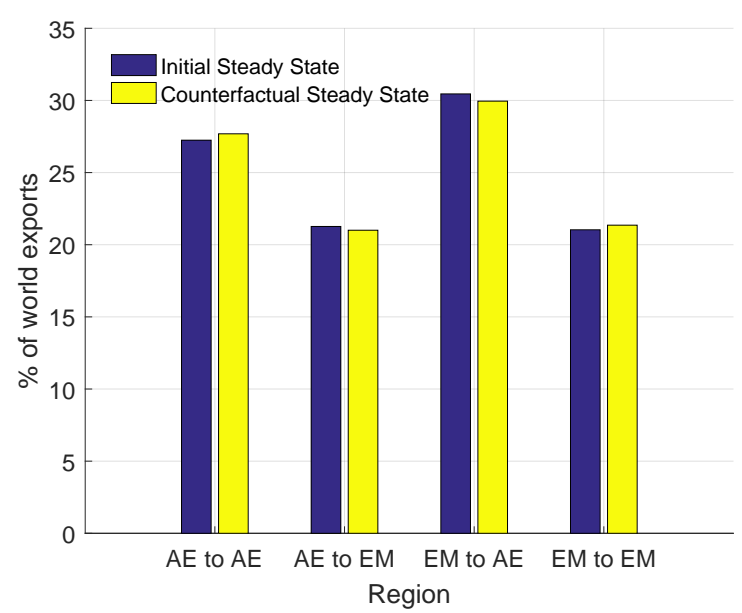


efficient, as global production is maximized at free trade. However, it is known that unilateral deviations by countries will be profitable. In fact, as shown by both Alvarez and Lucas (2007) and Costinot et al. (2015), there is always an argument for optimal tariffs larger than 0 for any country because even small countries are large in those goods in which they have a comparative advantage. In the framework of Eaton-Kortum with Frechet technology shocks, those goods produced by small and distant countries are precisely those in which these countries have a large comparative advantage and a large market share. When countries act strategically, it is less clear if countries would like to commit to free trade. This generally depends on parameters. However both Ossa (2014) and Bagwell et al. (2018) argue that the outcome of a global trade war will generally be worse than the outcome of multilateral bargaining. ${ }^{36}$

Because the literature has analyzed the impact of trade policy in the Eaton-Kortum setting, one may wonder if the outcome of a true Nash trade war and multilateral bargaining could be calculated in our model. Unfortunately, while an important avenue for future research, answering this question is difficult given the particulars of our setting. There are two complications that arise. First, the majority of papers that analyze trade policy in multi-country, multi-good settings do so with utility functions that do not have income effects, and in a static setting. As we have both income effects and dynamics in our model, the feedback from tariff revenue into consumption and savings and back into optimal tariffs implies that the standard "inverse elasticity formula" will not hold. Second, and more importantly, the presence of input-output linkages dramatically complicates the problem of even solving for optimal tariffs without country responses. As discussed by McLaren (2016), many results (e.g., Costinot et al. (2015)) on optimal tariffs in a Ricardian world rely on additively separable final demand, so that optimal tariffs conditional on factor prices can be solved good by good. The presence of input-output links breaks this additive separability, meaning that all tariffs must be solved jointly. Grant (2019) does this calculation in a simplified world of pure output and pure input goods, but there is no work, to the best of our knowledge, characterizing how these tariffs look in the most general setting. The tools for analyzing these tariffs computationally are only being developed (e.g., Bagwell et al. (2018)). However, there is important future work to be done in determining the multilateral bargaining tariffs that are optimal for EMs and seeing how they differ from current tariffs and from those under a global trade war.

\footnotetext{
${ }^{36}$ Nevertheless, Bagwell and Staiger do find that some countries would benefit from a trade war over current tariffs. This is a particularly interesting finding in light of current politics.
} 


\section{Discussion: Heckscher-Ohlin Forces and Transitional Dynamics}

In this section of the paper, we revisit the implications and limitations associated with the two departures of our model relative to the canonical general equilibrium models of international trade used for quantitative analysis. First we focus on the implications of HO forces for our results and then proceed to discuss the challenges faced when trying to solve transitional dynamics in our model and the limitations implied by our focus on steady-state comparisons.

\subsection{The Relevance of Heckscher-Ohlin Forces}

Fact 6 in Section 2 shows that the factor content of trade differs markedly across AEs and EMs. This fact motivated us to introduce HO-type comparative advantage into our quantitative model. However, one may ask, are these forces relevant for understanding the effects of rising trade barriers on EMs? In this section we argue that answer is yes. To gain a better understanding of the relevance of HO-type comparative advantage, we go back to our global trade war exercise and consider how the results would change if we consider a model without HO forces.

Figure 15: Exports by Sector in Initial Steady State

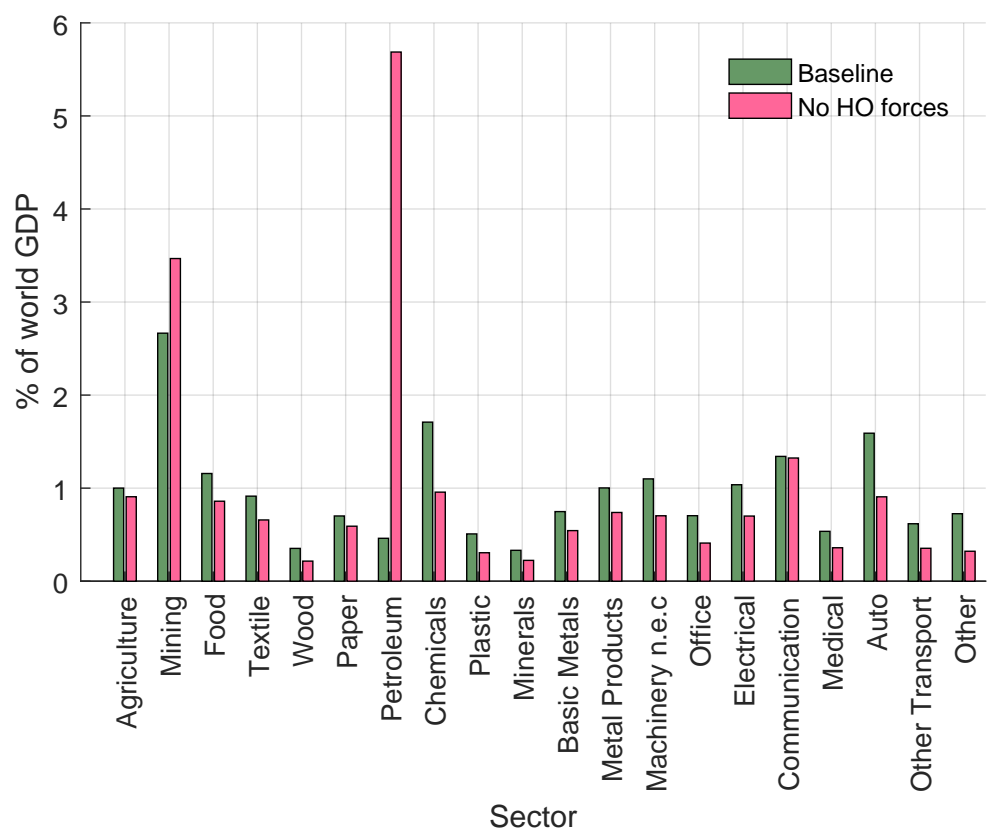

To do so, we assume that technologies in each country do not differ across sectors. That is, for every $i=1, \ldots, I$, we impose $\gamma_{i}^{j}=\gamma_{i}^{j^{\prime}}$ and $\psi_{i}^{j}=\psi_{i}^{j^{\prime}}$ for all $j, j^{\prime}=1, \ldots, J$. ${ }^{37}$ This assumption

\footnotetext{
${ }^{37}$ We choose the median technology in each country as the representative aggregate technology.
} 
implies that technologies across sectors only differ because of differences in productivities in the spirit of Ricardian comparative advantage. Under this new assumption, we recalibrate sectoral productivities and solve for the new levels of capital needed to rationalize the initial steady state. With this new model in hand, we can once again simulate the trade war.

Before doing so, it is worth asking how much trade differs across these models in steady state. Interestingly, the model without $\mathrm{HO}$ forces generates a level of world exports of 21.6 percent of world GDP, 2.4 percentage points greater than the 19.2 percent in our baseline model. ${ }^{38}$ Figure 15 shows world exports across sectors in the initial steady state of each model. The plot shows that the higher level of exports for the model without HO-type comparative advantage is driven by two sectors: mining and petroleum. This fact suggests that HO forces are particularly important to explain trade flows across countries for these two sectors. Therefore, if we abstract from these forces, all comparative advantage differences must be absorbed by productivity differences, which end up generating more trade given factor prices around the world.

Figure 16 presents the macroeconomic consequences of the global trade war for the model without HO forces as well as for our baseline model. Changes in real GDP are plotted in Figure 16a. Overall, the global trade war generates a drop in world GDP of 7.2 percent, more than 4 times larger than in our baseline model (1.6 percent). Interestingly, the role of capital accumulation as a driver of global GDP is equally important in both models. In our baseline model, endogenous capital accumulation explains 0.9 percentage points of the 1.6 percent drop in world GDP. Ignoring HO forces implies that endogenous capital accumulation explains 3.8 percentage points of the 7.2 drop in world GDP. In both cases, endogenous capital accumulation accounts for about half of the total decline in world GDP. However, when looking at AEs versus EMs, the differences in the predictions of each model become striking. Without HO forces, GDP drops by 7.8 and 6.5 percent in AEs and EMs, respectively, while in our baseline model these numbers are 1.7 and 1.5 percent, respectively. Hence, ignoring HO-type forces implies that we would overestimate the small difference in impacts across AEs and EMs.

One of our main results derived in Section 5.1 is that the effects of the global trade war are more heterogeneous across EMs than AEs. In particular, in our baseline model, the coefficient of variation of changes in GDP for EMs is more than twice as large (0.6) as that for AEs (0.24). However, this difference disappears - actually reverts - in the model without HO forces, leading to coefficients of variation for changes in GDP of 0.39 for AEs and 0.38 for EMs. Hence, the large heterogeneity the

\footnotetext{
${ }^{38}$ As a reference, world exports as a share of world GDP is 17.8 in our data.
} 
Figure 16: Global Trade War without HO-type Comparative Advantage: Macroeconomic Effects

(a) Gross Domestic Product

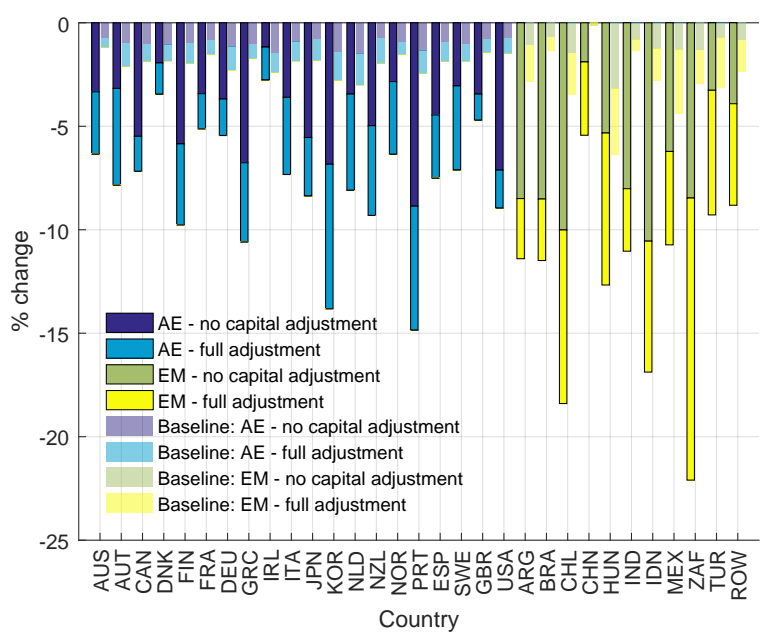

(c) Relative Price of Investment: $P_{i}^{X} / P_{i}^{C}$

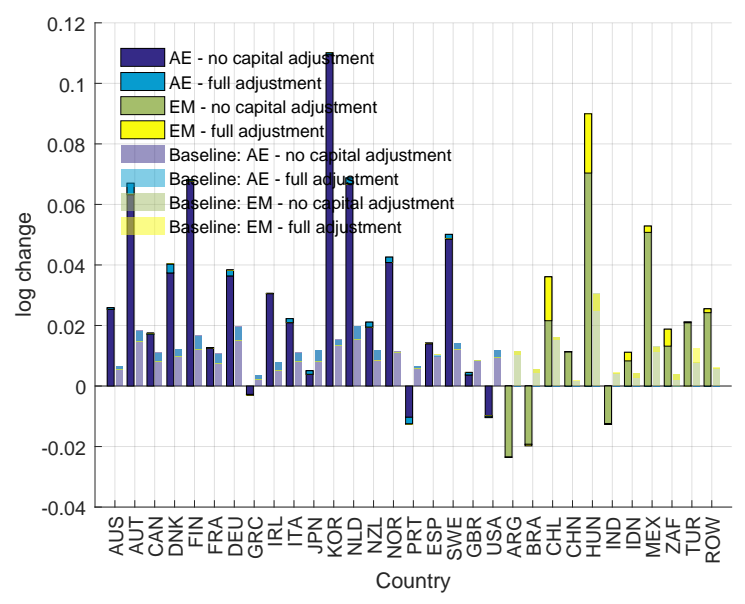

(e) World Exports by Sector

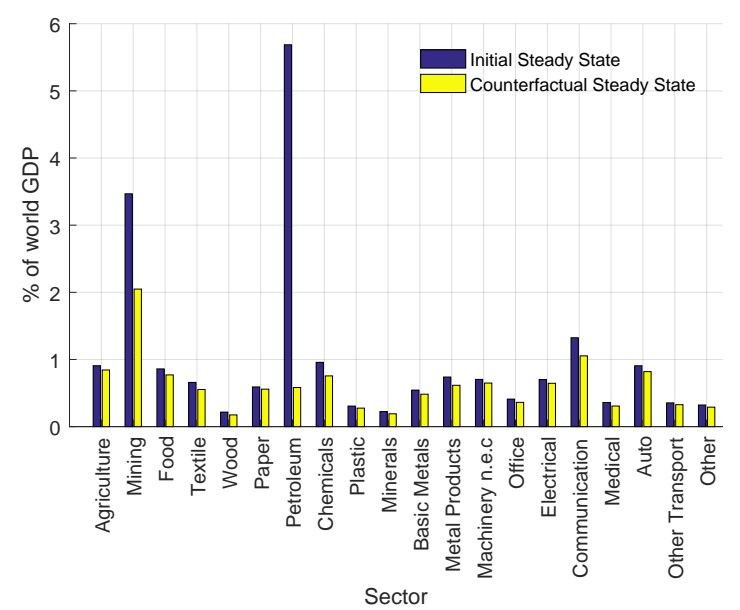

(b) Consumption

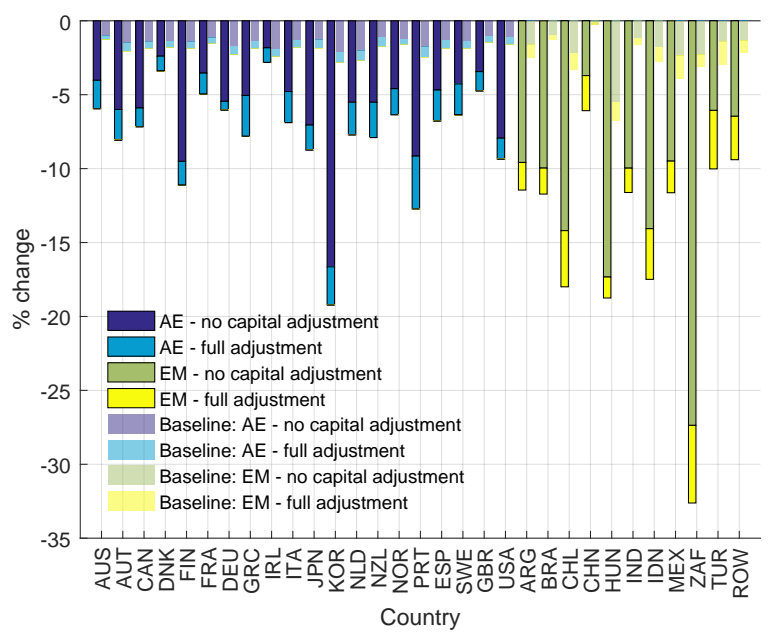

(d) Skill Premium: $w_{i}^{S} / w_{i}^{U}$

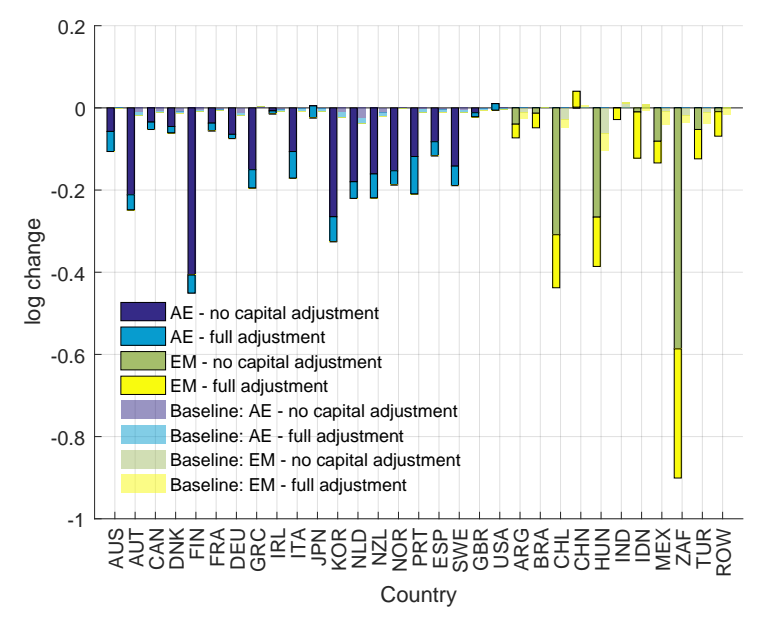

(f) Regional Exports

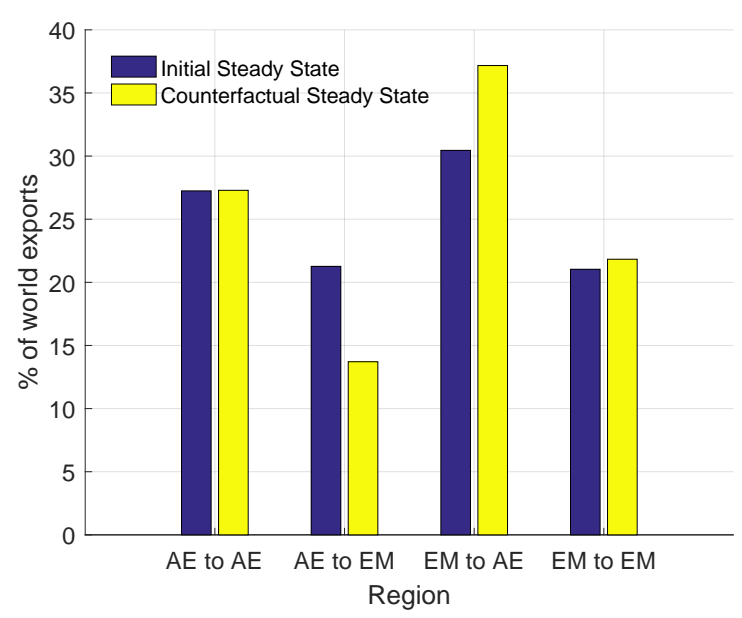


GDP effects of higher trade barriers in EMs arises because of HO forces.

The previous results suggest that HO comparative advantage dampens the effects of changes in trade barriers on EMs relative to AEs. If we think of $\mathrm{HO}$ forces as the main drivers of exports of EMs, then the fact that this type of comparative advantage is endogenous to changes in trade barriers - through capital accumulation-makes sense of our results. Lower trade barriers lead to a reinforcement of initial $\mathrm{HO}$ comparative advantage, while Ricardian comparative advantage differences are entirely exogenous in our model.

Panel 16b shows changes in consumption, which reflect changes in welfare. Changes in consumption are also overestimated when we do not incorporate HO forces. The drop in world consumption is 8.1, 5.7 percentage points of which occurs on impact, before any adjustment in capital stocks. While consumption in AEs drops by 8.5 percent, it only drops by 7.8 percent in EMs, compared with 1.8 and 1.6 percent drops in our baseline model. Higher trade barriers also generate significantly larger increases in the relative price of investment goods in almost all countries. Lastly, the effects on skill-premia are also amplified, as shown in Figure 16d.

When we focus on the differences in terms of trade flows, we find that world exports as a share of GDP drop by 8 percent, four times the decline when we take into account HO-type forces. Moreover, as world exports drop, the share of exports by each group of countries also changes. In particular, EMs overtake 8.5 percentage points of world exports. Interestingly, compared with the baseline model, trade among EMs is almost unchanged.

Note that the difference in the decline in exports across models is in line with the larger decline in world GDP when we abstract from HO forces. One possible way to understand these differences is based on the fact that, in the absence of HO forces, differences in country size become more important drivers of trade. Hence, to match observed trade flows, size becomes a more important margin of adjustment, which is reflected in differences in capital stocks in steady state. Differences in size must then explain changes in trade across countries, and feedback effects from trade into GDP and back can generate the outsized responses relative to our baseline model. Moreover, this story is in line with intra-group trade remaining almost unchanged in the absence of HO forces, as comparative advantage does not adjust in the long run.

\subsection{Transitional Dynamics}

The new quantitative general equilibrium models of international trade can accommodate a large degree of cross-country heterogeneity that the typical models used to study EMs do not consider. 
We have incorporated such heterogeneity into the analysis of the effects of trade barriers on EMs and have derived quantitative results by comparing steady states of the model. This approach implies that our results would only materialize in the long run and under permanent increases in trade barriers, as assumed in Section 5. However, we have not addressed how economies would transition from their initial to final steady states. Transitional dynamics can be particularly relevant if trade barriers were to increase temporarily rather than permanently as well as for welfare evaluations, as they ought to net out from steady-state effects the net gains of transitions and take into account the wealth redistribution across countries .

Solving for the transitional dynamics of our fully calibrated model used in Section 5 while maintaining the non-linear effects of trade costs represents a computational challenge. ${ }^{39}$ In this section we consider a simplified calibration of our model to focus on the analysis of transitional dynamics. The simplified calibration that we choose maintains the macroeconomic and financial elements of the model that play a key role in shaping transitional dynamics given shocks to trade costs. We use the model to analyze transitions after permanent and temporary increases in trade barriers based on the 2018-19 tariff increase scenario between China and the United States considered in Section 5.

In order to restrict the degree of heterogeneity in the model, we proceed as follows. For our calibration we consider four countries $(I=4)$ : the United States, China, AEs (other than the United States), and an EMs (other than China). We consider three sectors $(J=3)$, agriculture and mining, manufacturing, and services. In terms of technologies, we do not differentiate labor across skill levels - we assume that total labor and capital are the relevant factors of production and that they are aggregated in a Cobb-Douglas fashion into value added. Moreover, we abstract from HO-type comparative advantage by assuming that factor intensities and value-added shares in gross output do not vary across sectors, but are still country specific. ${ }^{40}$ We still allow input-output linkages to differ across countries.

One particular advantage of solving for transitional dynamics is that it allows us to address a limitation of our steady-state analysis in Section 5. In our previous calibration, we assumed that there is a positive cost $(\psi>0)$ of holding a net international financial asset (NIFA) position different from $\bar{B}_{i}$. This assumption allowed us to compute counterfactual steady states without the need to

\footnotetext{
${ }^{39}$ The degree of heterogeneity in the full calibration of our model implies that globally solving for transitions is computationally very intensive.

${ }^{40}$ These assumptions are implemented by defining $u_{i, t}$ as total labor and setting $\varphi_{i}^{j}=1$ for all $i$ and $j, \sigma=1$, and $\nu_{i}^{j}=\nu_{i}^{j^{\prime}}$ for all $j, j^{\prime}$ and $i$.
} 
compute transitions. ${ }^{41}$ However, this assumption also implies that changes in trade barriers cannot lead to wealth redistribution (bonds) across countries in the long run. We assume now that no such costs exist $(\psi=0)$ in order to account for wealth effects in our analysis. ${ }^{42}$

The rich heterogeneity in our baseline calibration gives rise to a very large state space of the model. The large state space implies that solving globally for transitions under our baseline calibration is computationally very intensive. Hence, this type of model has been mostly implemented in static environments (Parro, 2013). Recent works have made progress in extending these models to dynamic environments (Eaton et al., 2016; Reyes-Heroles, 2017; Ravikumar et al., 2019; Caliendo et al., 2019); however, these works do not incorporate heterogeneity nearly as rich as in our baseline calibration. ${ }^{43}$

We calibrate the initial steady state to the same data used in Section 5. Appendix C describes in detail our calibration approach. As previously mentioned, we consider two experiments, a permanent and a temporary six-year increase in tariffs in line with the 2018-19 increase in tariffs between the United States and China considered in Section 5. Our perfect foresight assumption implies that, after the initial unexpected increase in tariffs, all agents know their entire future path.

The results of a permanent increase in tariffs are shown in Figure 17. Higher trade barriers generate a drop in the return to capital in the United States and China (panel (e)), leading to a gradual but permanent decline in their capital stocks (panel (c)). The decline in capital is accompanied by a gradual and permanent drop in output and consumption in the United States and China (panels (a) and (b)) as well as a diversion of resources from domestic investment to foreign savings through an increase in their current accounts (panel (d)). Turning to EMs, note that the increase in tariffs initially has positive spillovers for this group of countries in terms of output and consumption (panels (a) and (b)). This initial increase is driven by the access to cheaper goods from the United States and China, which are used not only for consumption, but also for investment, leading to a temporary increase in EMs' capital stock and production capacity (panel (c)). As the world economy transitions to its new steady state, the effects of higher tariffs affect all economies

\footnotetext{
${ }^{41}$ In the absence of costs associated to NIFA positions, solving for the steady state of the model after a given shock to trade barriers requires knowledge of final NIFA positions. Given that this object is determined by countries' intertemporal budget constraints, recovering it requires the computation of full transitions. This requirement generates computational challenges as the new steady state of the model becomes endogenous to the relevant shock and initial conditions. An exception would be a model without capital accumulation in which the economy would reach the new steady state immediately after a shock.

${ }^{42}$ Mendoza and Tesar (1998) and Reyes-Heroles (2017) are examples of work that incorporate the wealth effects of changes in tax policy and trade barriers, respectively, in multi-country models.

${ }^{43}$ Most of these works consider a limited number of sectors (four at the most) (Eaton et al., 2016; Reyes-Heroles, 2017; Ravikumar et al., 2019) rather than the 40 in our baseline calibration; at the most two factors of production and therefore no capital-skill complementarity; a no international financial markets (Caliendo et al., 2019).
} 
Figure 17: Permanent Increase in Tariffs: Transitional Dynamics
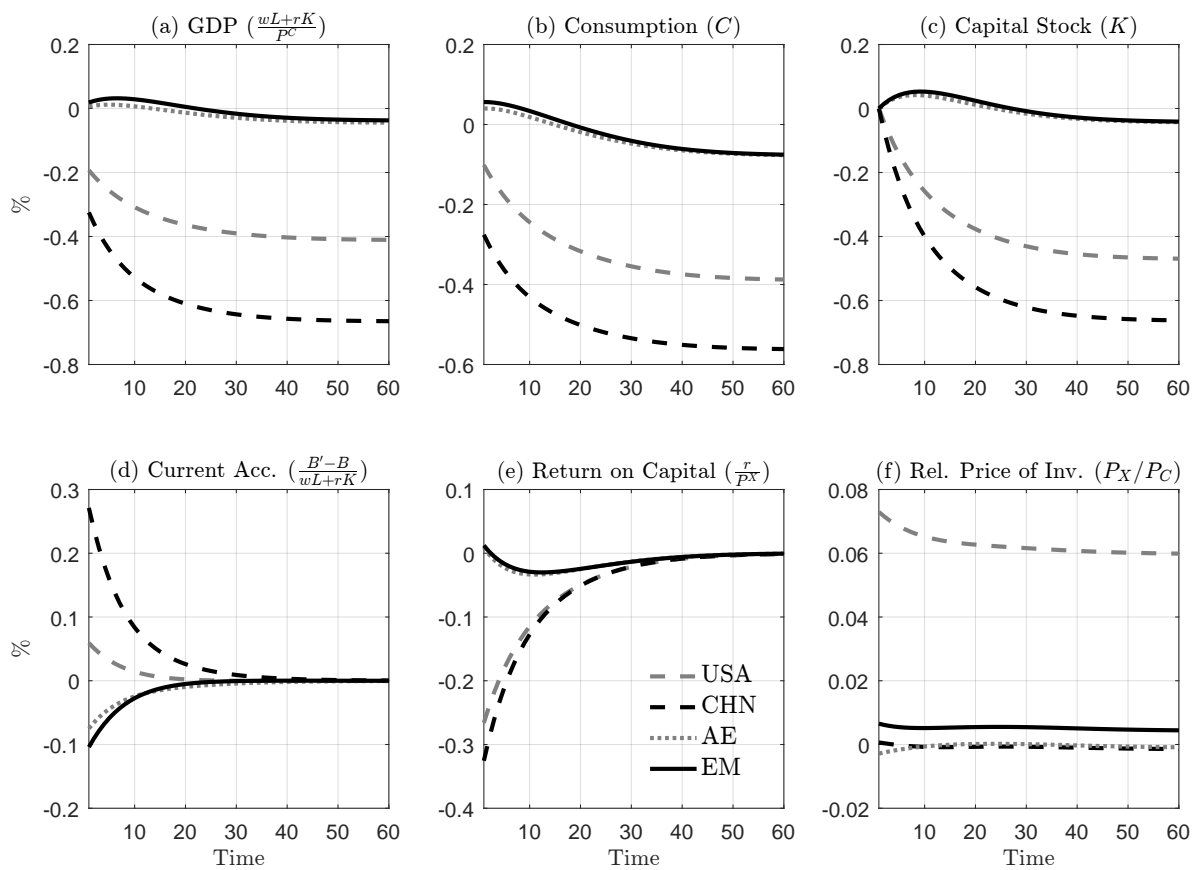

and output and consumption converge to levels below their initial ones.

We focus now on the welfare consequences of a permanent change in trade barriers. If we were to compare steady states only, we would overestimate the welfare losses from higher trade barriers. For instance, comparing steady states we would conclude that EMs suffer a 0.08 percent welfare loss computed in terms of consumption-equivalent variation. However, after netting out the transitional effects we find that EMs do not suffer welfare losses at all. For the United States and China, we would overestimate the welfare losses by 0.11 and 0.09 percentage points, respectively. We also find that economies change their NIFA positions in their new steady states. For instance, the United States and China start saving after the shock in order to use these savings in the future and smooth consumption once they reach their new permanently lower steady-state levels of output. Hence, the trade shock generates a redistribution of international financial wealth (excluding physical capital) across countries.

We turn now to the analysis of a temporary increase in tariffs. Our experiment considers the case in which high tariffs are in place for six periods and then go back to their original levels. The results of this temporary increase are shown in Figure 18. The temporary increase in barriers leads to a temporary decline in output in the United States and China (panel (a)). The decline in output is accompanied by a drop in the return on capital in both countries (panel (e)). While the temporary 
Figure 18: Temporary Increase in Tariffs: Transitional Dynamics
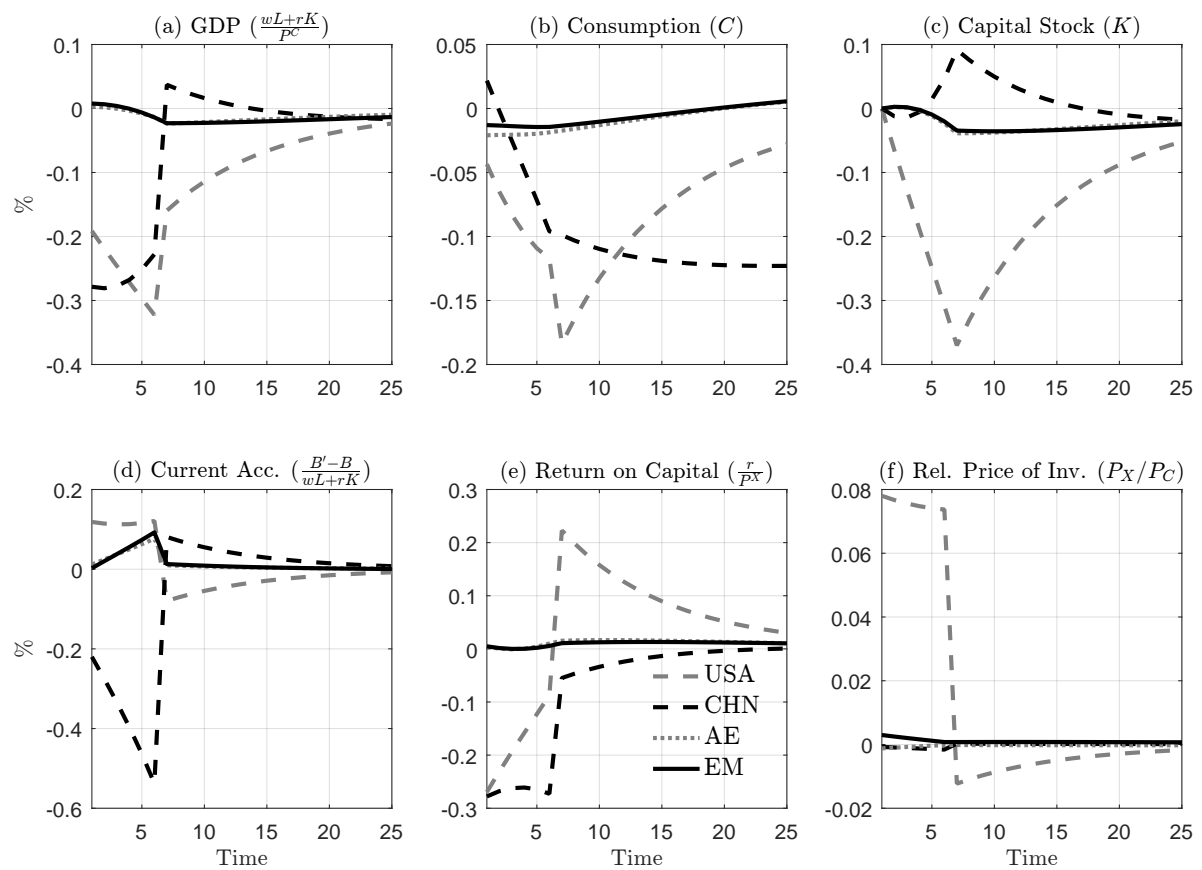

decline in output makes the United States and China want to borrow and smooth consumption by running a temporary current account deficit, the decline in their returns on capital also makes them want to halt investment and save abroad rather than domestically. General equilibrium forces, including the fact that AEs and EMs want to save, imply that China ends up borrowing enough to increase its capital stock (panel (c)) and output temporarily to smooth consumption, while the United States saves by lending to China, just like AEs and EMs do (panel (d)). All told, these forces lead to drastically different consumption paths for the United States and China even though the shock they experience is very similar. Considering temporary increases in trade barriers amplifies the forces driven by the asymmetries across countries.

Even though changes in welfare given the temporary nature of the shocks are small, an interesting result in this scenario is that we would underestimate (rather than overestimate) the welfare losses from the trade shock for the United States by 0.06 percentage point.

All told, our analysis of transitional dynamics under permanent and temporary increases in trade barriers shows that accounting for transitions is important to correctly compute the welfare implications of these shocks. At the same time, we learn from this analysis that missing on the rich cross-country heterogeneity that we incorporated into our full calibration can also have important implications for welfare computations. In particular, note that in in our simple calibration the 
welfare effects for the United States and China are reversed, as the latter loses more than the former in the long run, contrary to our results in Section 5. These results underscore the need to keep making progress on solving transitional dynamics of large dynamic quantitative general equilibrium models of trade.

\section{Conclusions}

One of the key challenges faced by EMs given the current state of the world economy is the potential increase in trade barriers. This challenge is particularly relevant for these economies given the major role that they currently play in global trade. A new geography of trade has emerged in which EMs are key heterogeneous players: not all EMs are alike. These facts are key in understanding how higher trade barriers can affect not only these economies, but the world in general.

We propose a quantitative, dynamic, general equilibrium, model of international trade to understand the long run harm of increasing trade barriers to EMs. Specifically, we estimate the impacts of three different counterfactual scenarios. First, a five percentage point global increase in tariffs lowers output in EMs and AEs by about 1.5 percent. However, EMs exhibit twice as much variation in outcomes as AEs. Second, in the event of a 'no trade deal' Brexit-a scenario in which multiple AEs raise tarrifs on each other - the spillovers onto EMs are positive, due to trade diversion, but small on average at a 0.1 percent increase in output. Once again, heterogeneity swamps the mean, with China and Turkey emerging as clear winners, and former Eastern Bloc countries like Hungary losing. Lastly, we find that if the tariffs imposed during the 2018-2019 trade tensions between China and the United States do not decline, China suffers, global GDP declines by 0.3 percent, but that spillovers onto other EMs actually raises their GDP by 0.22 percent.

\section{References}

Aguiar, Mark and Gita Gopinath, "Emerging Market Business Cycles: The Cycle Is the Trend," Journal of Political Economy, 2007, 115 (1), 69-102.

Alvarez, Fernando, "Capital accumulation and international trade," Journal of Monetary Economics, 2017, 91, 1 - 18 .

_ and Robert Jr. Lucas, "General equilibrium analysis of the Eaton-Kortum model of international trade," Journal of Monetary Economics, September 2007, 54 (6), 1726-1768. 
Amiti, Mary, Stephen J. Redding, and David E. Weinstein, "The Impact of the 2018 Tariffs on Prices and Welfare," Journal of Economic Perspectives, November 2019, 33 (4), 187-210.

Arkolakis, Costas, Arnaud Costinot, Dave Donaldson, and Andrs Rodrguez-Clare, "The Elusive Pro-Competitive Effects of Trade," The Review of Economic Studies, 01 2018, 86 (1), $46-80$.

Bagwell, Kyle, Robert W. Staiger, and Ali Yurukoglu, "Quantitative Analysis of MultiParty Tariff Negotiations," NBER Working Papers 24273, National Bureau of Economic Research, Inc February 2018.

Burstein, Ariel and Jonathan Vogel, "International Trade, Technology, and the Skill Premium," Journal of Political Economy, 2017, 125 (5), 1356-1412.

_ , Eduardo Morales, and Jonathan Vogel, "Changes in Between-Group Inequality: Computers, Occupations, and International Trade," American Economic Journal: Macroeconomics, April 2019, $11(2), 348-400$.

Bussière, Matthieu, Giovanni Callegari, Fabio Ghironi, Giulia Sestieri, and Norihiko Yamano, "Estimating Trade Elasticities: Demand Composition and the Trade Collapse of 2008-2009," American Economic Journal: Macroeconomics, July 2013, 5 (3), 118-51.

Caliendo, Lorenzo and Fernando Parro, "Estimates of the Trade and Welfare Effects of NAFTA," The Review of Economic Studies, 2015, 82 (1), 1-44.

_, Maximiliano Dvorkin, and Fernando Parro, "Trade and Labor Market Dynamics: General Equilibrium Analysis of the China Trade Shock," Econometrica, 2019, 87 (3), 741-835.

Charbonneau, Karyne B. and Anthony Landry, "The Trade War in Numbers," Technical Report, Bank of Canada Staff Working Paper 2018-57 2018.

Costinot, Arnaud, Dave Donaldson, Jonathan Vogel, and Ivn Werning, "Comparative Advantage and Optimal Trade Policy," The Quarterly Journal of Economics, 2015, 130 (2), 659-702.

Cravino, Javier and Sebastian Sotelo, "Trade-Induced Structural Change and the Skill Premium," American Economic Journal: Macroeconomics, July 2019, 11 (3), 289-326. 
Davis, Donald R and David E Weinstein, "An account of global factor trade," American Economic Review, 2001, 91 (5), 1423-1453.

Eaton, Jonathan and Samuel Kortum, "Trade in capital goods," European Economic Review, 2001, 45 (7), 1195 - 1235. International Seminar On Macroeconomics.

_ and _, "Technology, Geography, and Trade," Econometrica, 2002, 70 (5), 1741-1779.

_, _, Brent Neiman, and John Romalis, "Trade and the Global Recession," American Economic Review, November 2016, 106 (11), 3401-38.

Feenstra, Robert C. and Alan M. Taylor, International Trade Handbook 2017.

Flaaen, Arron and Justin Pirce, "Disentangling the Effects of the 2018-2019 Tariffs on a Globally Connected U.S. Manufacturing Sector," Finance and Economics Discussion Series Divisions of Research Statistics and Monetary Affairs Working Paper-086, 2019.

García-Cicco, Javier, Roberto Pancrazi, and Martín Uribe, "Real Business Cycles in Emerging Countries?," American Economic Review, December 2010, 100 (5), 2510-31.

Grant, Matthew, "Why special economic zones? Using trade policy to discriminate across importers," Unpublished Manuscript, Stanford University, 2019.

Hanson, Gordon H., "The Rise of Middle Kingdoms: Emerging Economies in Global Trade," Journal of Economic Perspectives, May 2012, 26 (2), 41-64.

IMF, "World Economic Outlook," Technical Report, April 2019 World Economic Outlook Analytical Chapter 42019.

Johnson, Robert C., "Five Facts about Value-Added Exports and Implications for Macroeconomics and Trade Research," Journal of Economic Perspectives, May 2014, 28 (2), 119-42.

Levchenko, Andrei A. and Jing Zhang, "The evolution of comparative advantage: Measurement and welfare implications," Journal of Monetary Economics, 2016, 78, 96 - 111.

McLaren, J., "Chapter 2 - The Political Economy of Commercial Policy," in Kyle Bagwell and Robert W. Staiger, eds., Kyle Bagwell and Robert W. Staiger, eds., Vol. 1 of Handbook of Commercial Policy, North-Holland, 2016, pp. 109 - 159. 
Mendoza, Enrique G., "Sudden Stops, Financial Crises, and Leverage," American Economic Review, December 2010, 100 (5), 1941-66.

Mendoza, Enrique G and Linda L Tesar, "The international ramifications of tax reforms: supply-side economics in a global economy," American Economic Review, 1998, pp. 226-245.

Montiel, Peter J, Macroeconomics in emerging markets, Cambridge University Press, 2011.

Morrow, Peter M. and Daniel Trefler, "Endowments, Skill-Biased Technology, and Factor Prices: A Unified Approach to Trade," NBER Working Papers 24078, National Bureau of Economic Research, Inc November 2017.

Neumeyer, Pablo A. and Fabrizio Perri, "Business Cycles in Emerging Economies: The Role of Interest rates," Journal of Monetary Economics, 2005, 52 (2), 345 - 380.

Ossa, Ralph, "Trade Wars and Trade Talks with Data," American Economic Review, December 2014, 104 (12), 4104-4146.

Parro, Fernando, "Capital-Skill Complementarity and the Skill Premium in a Quantitative Model of Trade," American Economic Journal: Macroeconomics, April 2013, 5 (2), 72-117.

Ravikumar, B., Ana Maria Santacreu, and Michael Sposi, "Capital accumulation and dynamic gains from trade," Journal of International Economics, 2019, 119, 93 - 110.

Reyes-Heroles, Ricardo, "The Role of Trade Costs in the Surge of Trade Imbalances," 2017. (Manuscript).

Timmer, Marcel P., Abdul Azeez Erumban, Bart Los, Robert Stehrer, and Gaaitzen J. de Vries, "Slicing Up Global Value Chains," Journal of Economic Perspectives, May 2014, 28 (2), 99-118.

Trefler, Daniel, "The case of the missing trade and other mysteries," The American Economic Review, 1995, pp. 1029-1046.

- and Susan Chun Zhu, "The structure of factor content predictions," Journal of International Economics, November 2010, 82 (2), 195-207.

UNCTAD, "The new geography of international economic relations," Background Paper No. 1, 2004 . 
Uribe, Martín and Vivian Z. Yue, "Country Spreads and Emerging Countries: Who Drives Whom?," Journal of International Economics, 2006, 69 (1), 6 - 36. Emerging Markets.

Végh, Carlos A, Open economy macroeconomics in developing countries, MIT press, 2013. 


\section{A Appendix: Data Sources and Calibration}

\section{A.1 Facts 1-5}

To document facts 1 through 5, we use data at the HS-6 level from UN Comtrade from 1996 to 2016. We rely on the BEC classification system outlined in Appendix B to classify traded goods as intermediate, consumption and capital goods.

We consider 56 countries and one rest of the world aggregate for our analysis of these facts. We classify 21 countries as EMs: Argentina, Bulgaria, Brazil, China, Chile, Colombia, Croatia, Hungary, India, Indonesia, Mexico, Malaysia, Peru, Philippines, Poland, Romania, Russia, South Africa, Thailand, Turkey, and Vietnam. We also classify the rest of the world aggregate as an EM. The AEs encompass 35 countries: Australia, Austria, Belgium, Canada, Cyprus, Czech Republic, Denmark, Spain, Estonia, Finland, France, Germany, Greece, Hong Kong, Ireland, Israel, Italy, Japan, Lithuania, Latvia, Luxembourg, Malta, Netherlands, Norway, New Zealand, Portugal, Singapore, Slovakia, Slovenia, South Korea, Sweden, Switzerland, Taiwan, the United Kingdom, and the United States.

These 56 countries have trade data available for the entire period and represent $91 \%$ of world trade and $91 \%$ of world GDP. The AE and EM classification is based on that of the IMF World Economic Outlook (WEO) for 2018.

Data on nominal GDP to construct openness measures come from the IMF WEO for 1996 to 2016. We include 56 main countries, including 34 AEs, 22 EMs, and one aggregate rest of the world.

\section{A.2 Fact 6}

To document fact 6, we consider data from the World Input-Output Database (WIOD) 2013 release and the associated 2014 release of the Socio Economic Accounts (SEA). The SEA considers three different types of labor according to skill levels: low, medium and high skill. These data are readily available from 1995 to 2009.

\section{A.3 Model Calibration}

For the calibration of the model we consider 31 countries: 30 core countries and an aggregate that we label rest of the world (ROW). The following is the list of the countries we consider to calibrate our model. 
- AEs [20] Australia (AUS), Austria (AUT), Germany (DEU), Canada (CAN), Denmark (DNK), Spain (ESP), Finland (FIN), France (FRA), Italy (ITA), Greece (GRC), Ireland (IRL), Japan (JPN), Korea (KOR), the Netherlands (NLD), New Zealand (NZL), Norway (NOR), Portugal (PRT), Sweden (SWE), the United Kingdom (GBR), and the United States (USA).

- EMEs [11] Argentina (ARG), Brazil (BRA), Chile (CHL), China (CHN), Hungary (HUN), Indonesia (IDN), India (IND), Mexico (MEX), Turkey (TUR), South Africa (ZAF), Rest of the World (ROW).

Table 2 shows the sectors we consider, which are the same as in as in Caliendo and Parro (2015).

Table 2: Sectors

\begin{tabular}{llll|llll}
\hline \hline \multicolumn{3}{c|}{ Tradable } & \multicolumn{4}{c}{ Non-Tradable } \\
\hline 1 & Agriculture & 11 & Basic metals & 21 & Electricity & 31 & Real estate \\
2 & Mining & 12 & Metal products & 22 & Construction & 32 & Renting machinery \\
3 & Food & 13 & Machinery nec & 23 & Retail & 33 & Computer \\
4 & Textile & 14 & Office & 24 & Hotels & 34 & R\&D \\
5 & Wood & 15 & Electrical & 25 & Land transport & 35 & Other business \\
6 & Paper & 16 & Communication & 26 & Water transport & 36 & Public \\
7 & Petroleum & 17 & Medical & 27 & Air transport & 37 & Education \\
8 & Chemicals & 18 & Auto & 28 & Aux transport & 38 & Health \\
9 & Plastic & 19 & Other transport & 29 & Post & 39 & Other services \\
10 & Minerals & 20 & Other & 30 & Finance & 40 & Private \\
\hline \hline
\end{tabular}

1. Trade We use bilateral trade from the United Nations Statistical Division Commodity Trade (UNCOMTRADE) database for 2016 at the Harmonized System 6-digit (HS-6) level. We include 30 separate countries, which together account for more than 85 percent of world GDP, and a ROW modeled as one aggregate block. ${ }^{44}$ We map these HS-6 product level codes to the 20 tradable sectors as in Caliendo and Parro (2015) using the HS-ISIC concordance tables.

2. Tariffs We collect tariff data for 2016 from the United Nations Statistical Division-Trade Analysis and Information System (UNCTAD-TRAINS) and Most-Favored Nation (MFN) databases for the same 30 countries and a ROW average. The UNCTAD TRAINS data contain bilateral tariffs at the Harmonized System 6-digit (HS-6) product level. The MFN data provide importer-specific MFN tariff rates, which is also at the HS-6 product level.

\footnotetext{
${ }^{44}$ The 30 countries include Argentina, Australia, Austria, Brazil, Canada, Chile, China, Denmark, Finland, France, Germany, Greece, Hungary, India, Indonesia, Ireland, Italy, Japan, Mexico, the Netherlands, New Zealand, Norway, Portugal, South Africa, South Korea, Spain, Sweden, Turkey, the United Kingdom, and the United States.
} 
We then aggregate the HS-6 product level tariff data to sectoral tariffs by using bilateral trade weights for all the HS-6 level trade flows within a sector. All told, we compute 31 by 31 bilateral tariffs for each of the 20 tradable sectors in 2016 and assume infinitely large trade barriers for the 20 non-tradable sectors to serve as our baseline. The implemented and proposed tariffs are taken from the lists released by the United States Trade Representative (USTR) and China's Ministry of Commerce (MOFCOM). The published lists typically disaggregate goods at the HS-10 product level. Therefore, when computing the imposed and prospective tariffs for our counterfactual analysis, we convert the HS-10 product level codes to HS-6 product level codes.

3. Input-output tables We use the World Input-Output Database (WIOD) ${ }^{45}$ for 2014 to compute the input-output coefficients as the total dollar value of an input sector's intermediate goods divided by the total dollar value of the output sector's inputs. The last year with available data in the 2016 release of the WIOD is 2014. We supplement these data with the OECD's input-output (I-O) tables for 2011 for those countries that are not included in WIOD.

4. Gross output and value added We use sectoral gross output and value added data from the OECD STAN database for 2016. We supplement these data with the sectoral gross output and value added data from the Socio Economic Accounts (SEA), the United Nations' INDSTAT2 and the National Accounts databases. We construct value added shares for our model as the ratio of a sector's value added to gross output.

5. Factors of Production We consider aggregate data on capital and labor from the Penn World Tables (PWT) latest release. We then consider skill share provided in the SEA release 2014 of the WIOD. We define low-skill workers as those workers classified as either low skill or medium skill in the data for the year 2009, which is the latest year for which these data are available.

6. Sectoral Expenditure Shares To construct sectoral expenditure shares, we consider data from the WIOD 2016 release for the year 2014.

7. Factor and Sectoral prices To recover data on factor prices, we rely on data for factor compensations and endowments. We consider factor compensation for capital and total labor for 2014 from the SEA 2016 release. We then use labor compensation shares across skill groups from the

\footnotetext{
${ }^{45}$ http://www.wiod.org/release16
} 
SEA 2014 release for the year 2009. This procedure is similar to the one followed in Reyes-Heroles (2017). We estimate sectoral prices by exploiting the sector-specific gravity structure of our model following the exact same procedure as in Reyes-Heroles (2017).

\section{B Appendix: BEC Goods Classification}

1. Intermediate goods

- 121-Food and beverages, processed, mainly for industry

- 21-Industrial supplies not elsewhere specified, primary

- 22-Industrial supplies not elsewhere specified, processed

- 322-Fuels and lubricants, processed (other than motor spirit)

- 42-Parts and accessories of capital goods (except transport equipment)

- 53-Parts and accessories of transport equipment

2. Commodities (excluding oil)

- 111-Food and beverages, primary, mainly for industry

- 112-Food and beverages, primary, mainly for household consumption

3. Capital goods

- 41-Capital goods (except transport equipment)

- 521-Transport equipment, industrial

4. Other

- 122-Food and beverages, processed, mainly for household consumption

- 31-Fuels and lubricants, primary

- 321-Fuels and lubricants, processed (motor spirit)

- 51-Passenger motor cars

- 521-Transport equipment, industrial

- 522-Transport equipment, non-industrial

- 61-Consumer goods not elsewhere specified, durable

- 62-Consumer goods not elsewhere specified, semi-durable

- 63-Consumer goods not elsewhere specified, non-durable

- 7-Goods not elsewhere specified

\section{Appendix: Calibration of Model in Section 6.2}

To calibrate the version of our model considered in Section 6.2, we first aggregate the relevant data considered in Section 5 to four countries (United States, China, AEs excl. the United States, and EMs excluding China) and three sectors (agriculture and mining, manufacturing, and services). We then follow the same procedure as in Section 5 to discipline parameters and labor endowments. However, we choose a different strategy to calibrate sectoral productivities. First, we recover 
trade barriers using Head-Ries indices, implying that we assume symmetric trade barriers. Then we proceed to set investment efficiencies equal to one around the world and calibrate sectoral productivities such that, in its initial steady state, the model matches as close as possible data on domestic trade shares and country GDP shares. It is possible to consider this strategy given that solving for the steady state of the smaller model is significantly faster than for the baseline calibration of our model.

\section{Appendix: Additional Figures}

Figure 19: Total exports (\$ trillions)

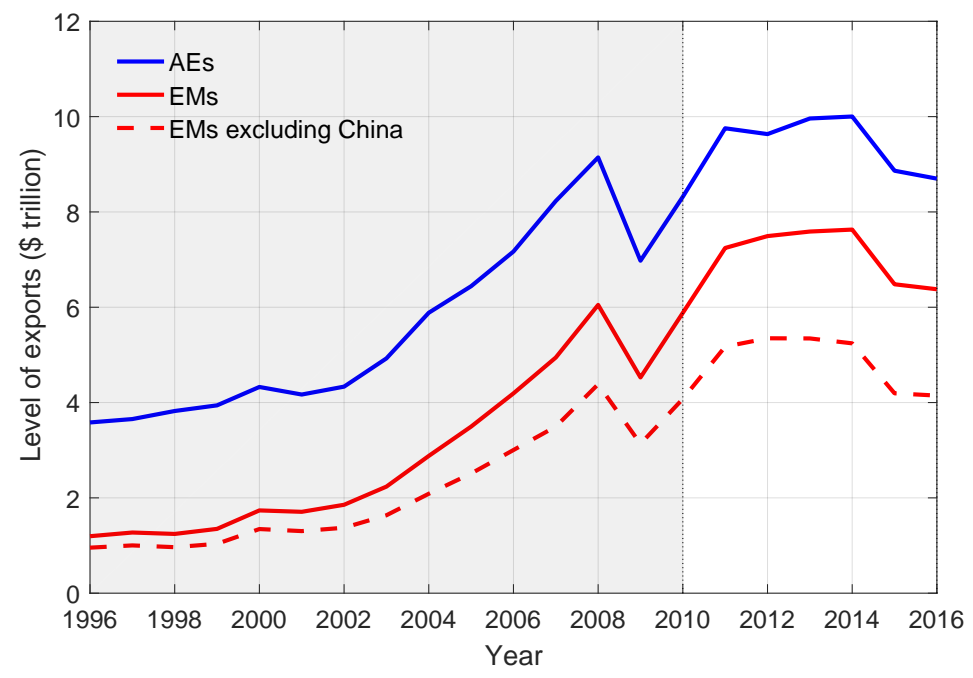


Figure 20: EM and AE Trade Openness (exports + imports as a share of GDP)

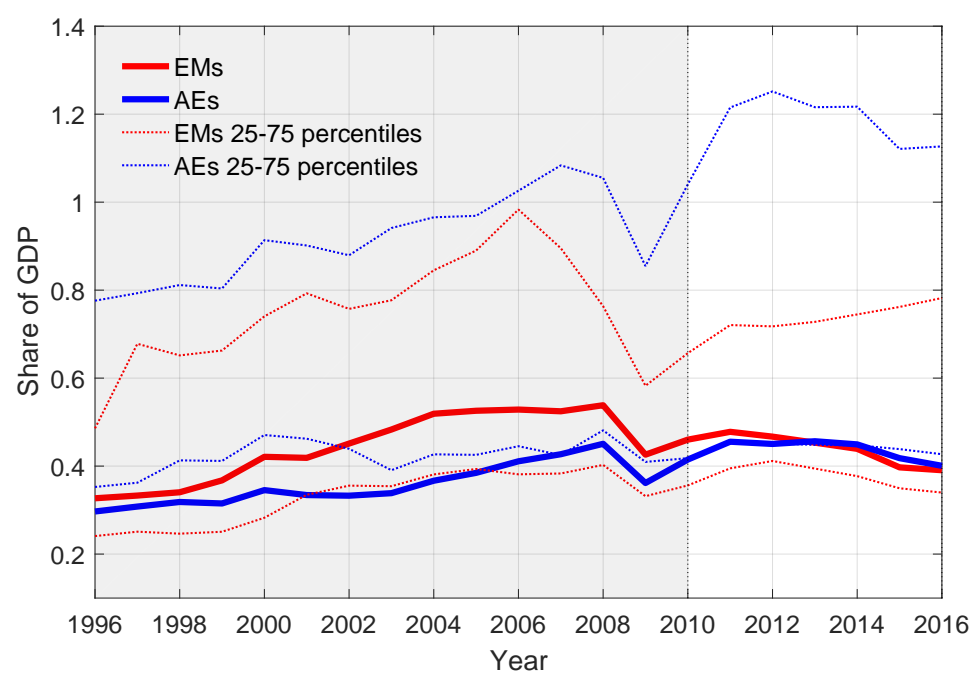

Figure 21: EM and AE Trade Openness excluding China (exports + imports as a share of GDP)

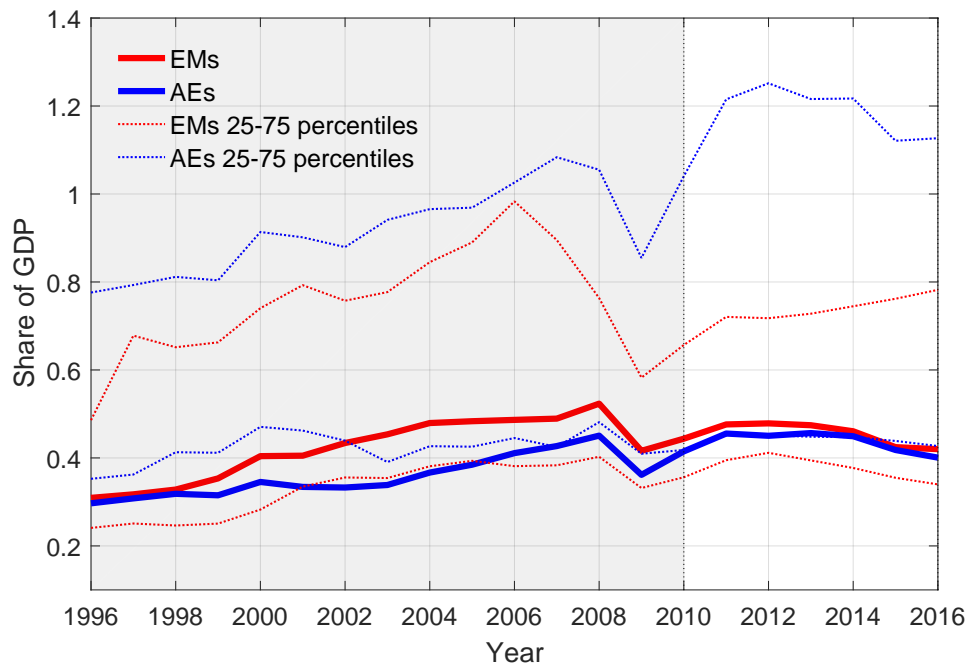


Figure 22: EM and AE Trade Openness (imports as a share of GDP)

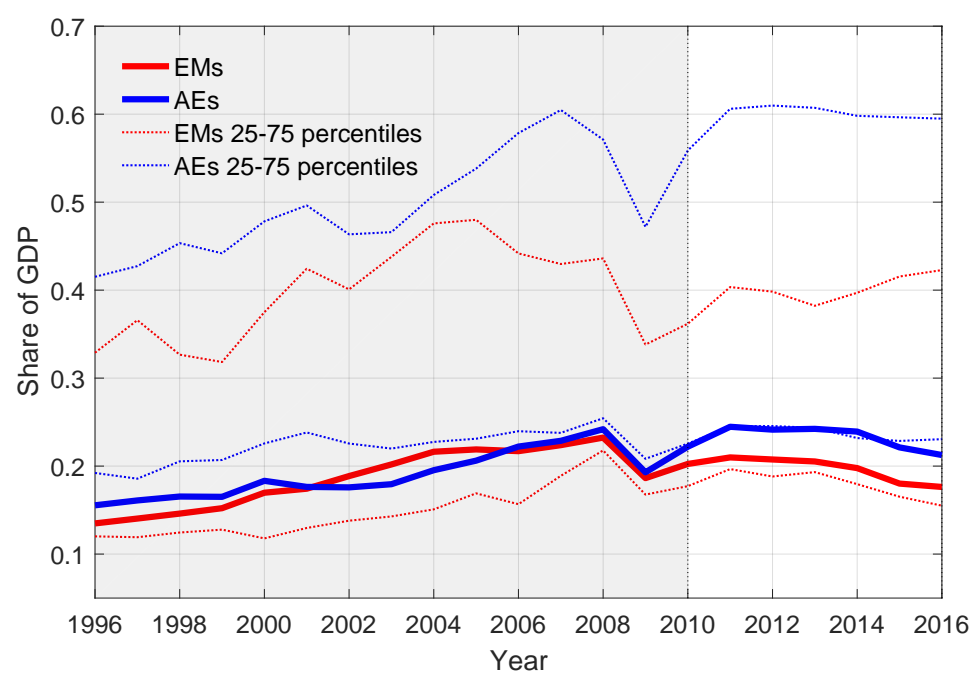

Figure 23: EM and AE Trade Openness excluding China (imports as a share of GDP)

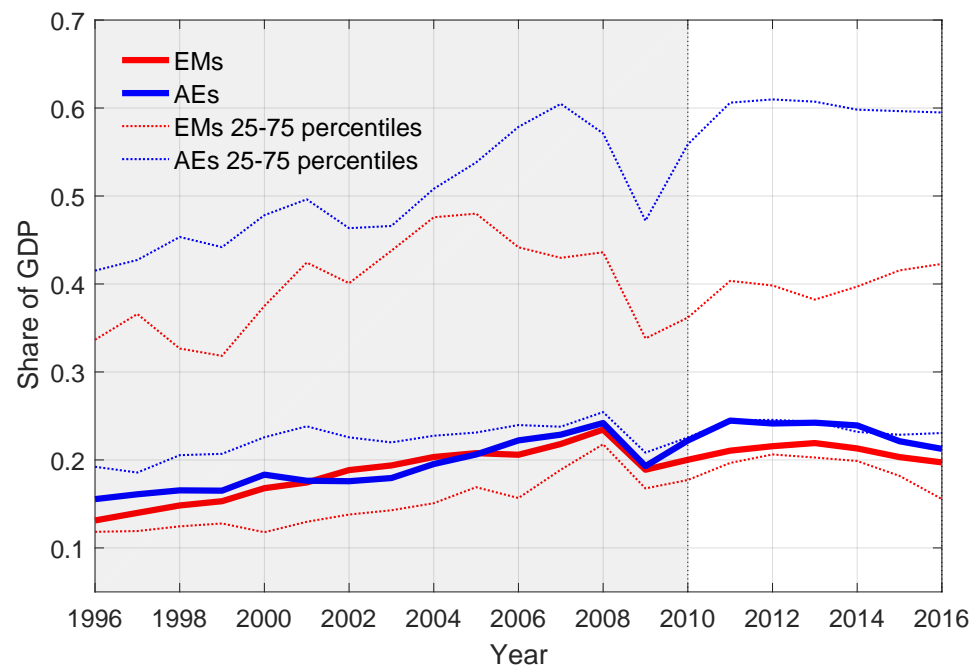


Figure 24: Total intra- and inter-group exports (\$ trillions)

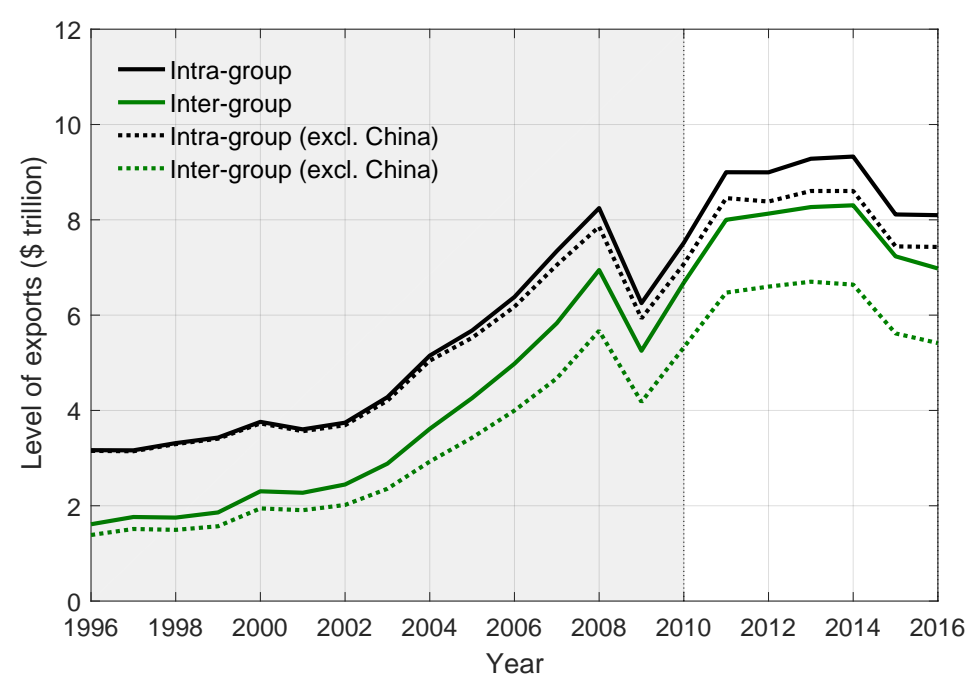

Figure 25: Intra-group exports (\$ trillions)

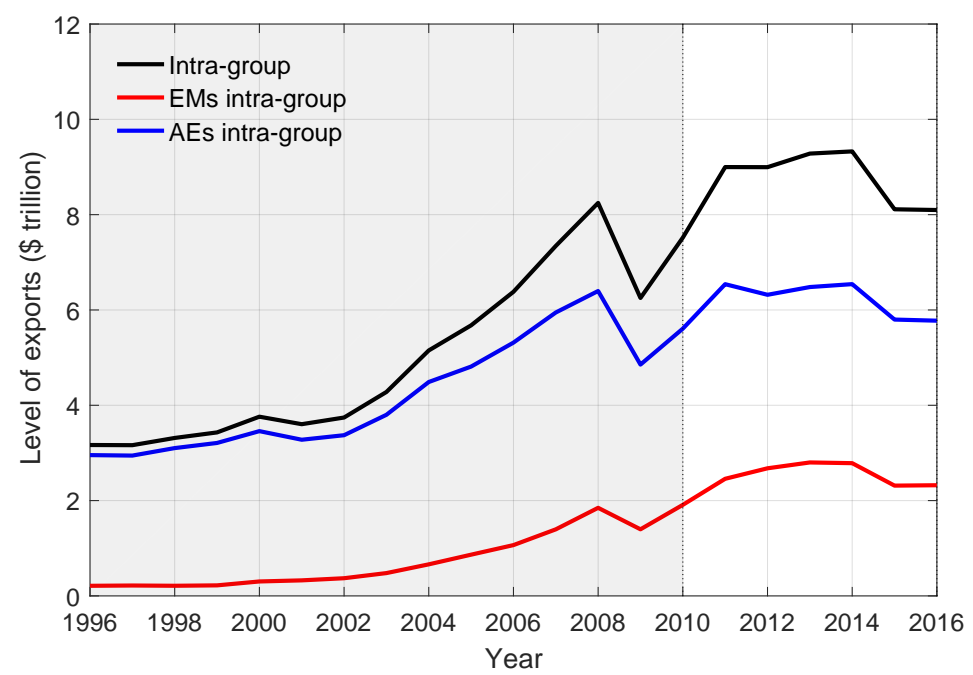


Figure 26: Importance of EMs in Intermediate and Capital Goods Trade

(a) Intermediate Goods (\$ trillions)

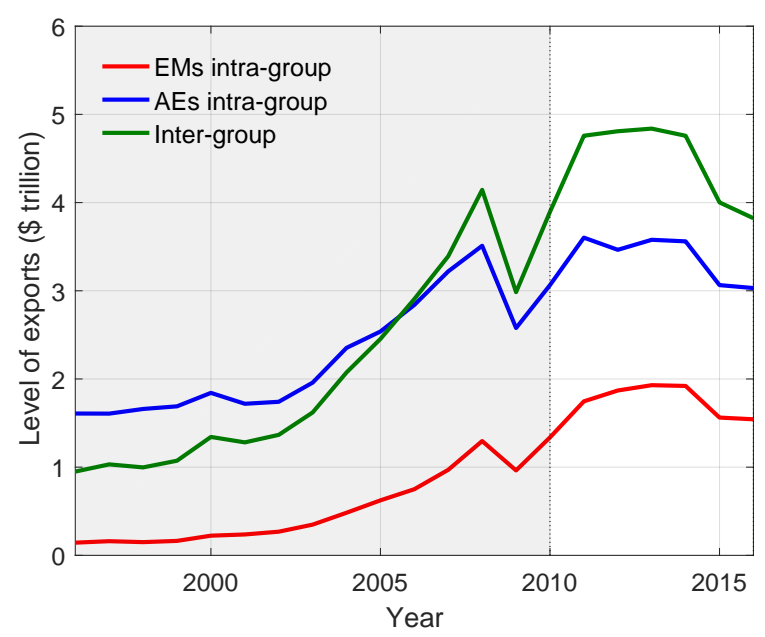

(b) Capital Goods (\$ trillions)

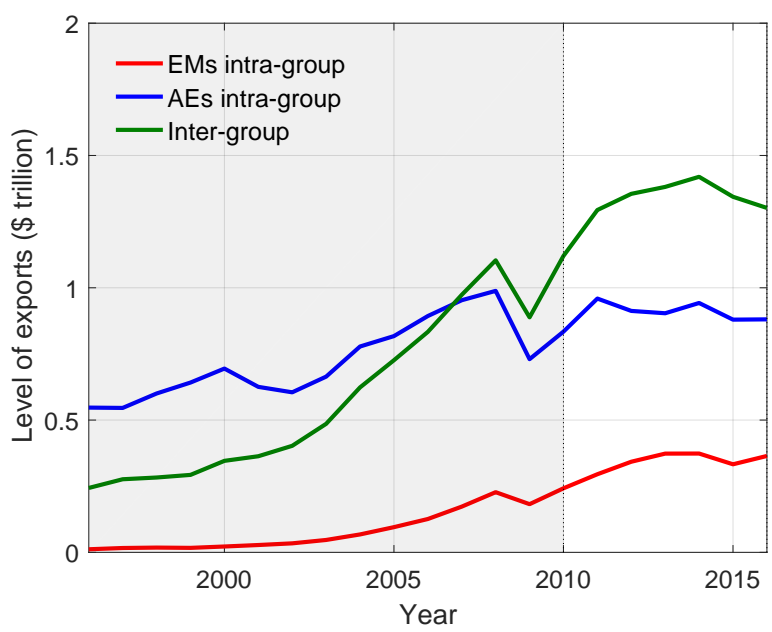

Figure 27: Trade among EMs (\$ trillions)
(a) Intermediate Goods
(b) Non-oil Commodities
(c) Capital Goods
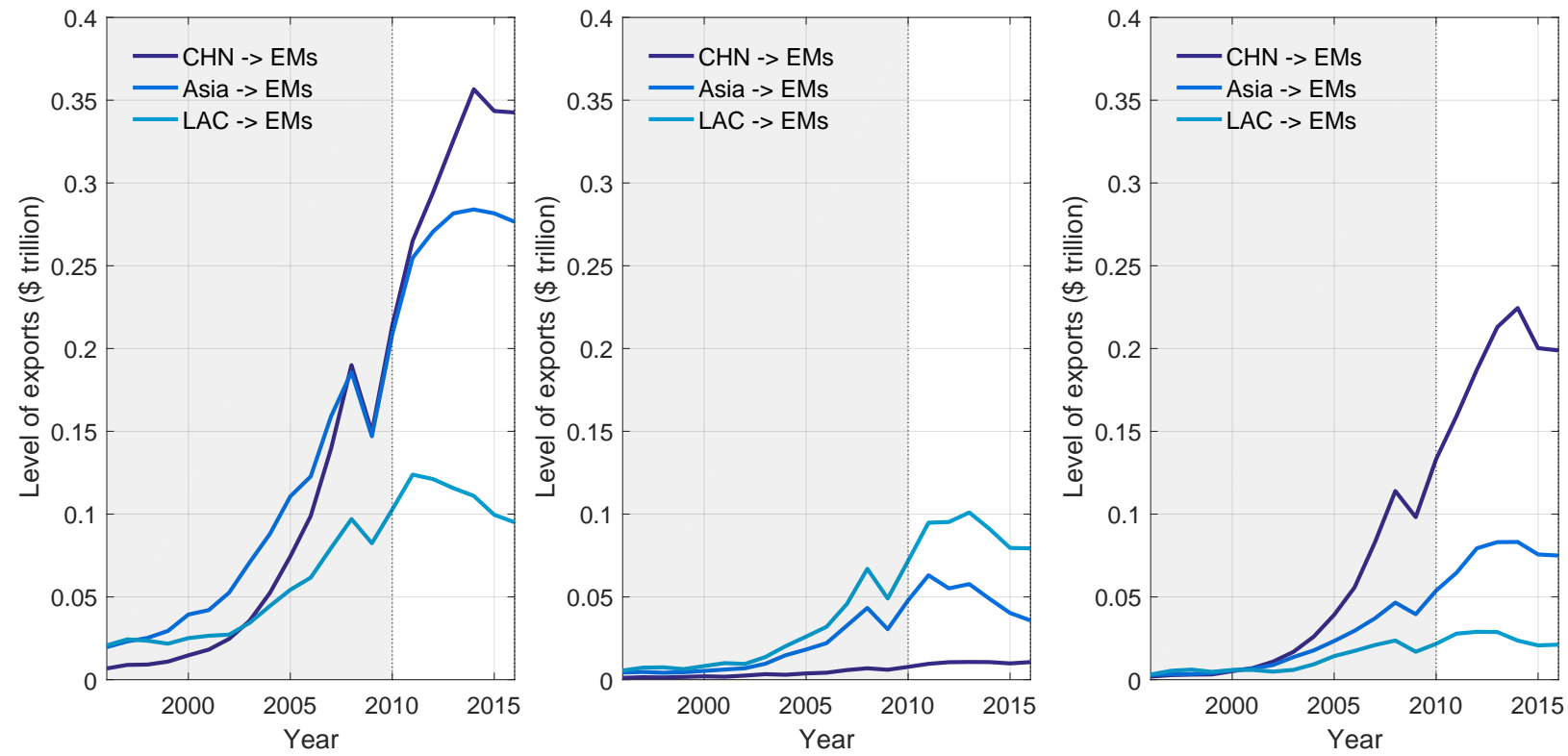